Accepted refereed manuscript of:

Fritzsche A, Schröder C, Wieczorek A, Handel M, Ritschel T \& Totsche KU (2015) Structure and composition of Fe-OM coprecipitates that form in soil-derived solutions, Geochimica et Cosmochimica Acta, 169, pp. 167-183.

DOI: $\underline{10.1016 / \text { i.gca.2015.07.041 }}$

(C) 2015, Elsevier. Licensed under the Creative Commons AttributionNonCommercial-NoDerivatives 4.0 International http://creativecommons.org/licenses/by-nc-nd/4.0/ 


\section{Structure and composition of Fe-OM co-precipitates that form in soil-derived solutions}

Andreas Fritzsche ${ }^{a,{ }^{*}}$, Christian Schröder ${ }^{b, c, 1}$, Arkadiusz K. Wieczorek ${ }^{\mathrm{a}}$, Matthias Händel ${ }^{\mathrm{a}}$, Thomas Ritschel ${ }^{a}$, Kai U. Totsche ${ }^{a}$

${ }^{a}$ Institut für Geowissenschaften, Friedrich-Schiller-Universität Jena, D-07749 Jena, Germany

${ }^{\text {b }}$ Lehrstuhl für Hydrologie, Universität Bayreuth, D-95440 Bayreuth, Germany

c Zentrum für Angewandte Geowissenschaften, Eberhard-Karls-Universität Tübingen, D-72074 Tübingen, Germany

* Corresponding author. Tel.: +49 3641948 715; fax: +49 3641948 742; e-mail: a.fritzsche@unijena.de

${ }^{1}$ Present Address: Biological and Environmental Sciences, School of Natural Sciences, University of Stirling, Stirling FK9 4LA, UK. 


\section{Abstract}

Iron oxides represent a substantial fraction of secondary minerals and particularly affect the reactive properties of natural systems in which they formed, e.g. in soils and sediments. Yet, it is still obscure how transient conditions in the solution will affect the properties of in situ precipitated Fe oxides. Transient compositions, i.e. compositions that change with time, arise due to predominant non-equilibrium states in natural systems, e.g. between liquid and solid phases in soils. In this study, we characterize Fe-OM co-precipitates that formed in pH-neutral exfiltrates from anoxic topsoils under transient conditions. We applied soil column outflow experiments, in which $\mathrm{Fe}^{2+}$ was discharged with the effluent from anoxic soil and subsequently oxidized in the effluent due to contact with air. Our study features three novel aspects being unconsidered so far: i) the transient composition of soil-derived solutions, ii) that pedogenic Fe oxides instead of $\mathrm{Fe}$ salts serve as major source for $\mathrm{Fe}^{2+}$ in soil solution and iii) the presence of exclusively soil-derived organic and inorganic compounds during precipitation. The experiments were carried out with two topsoil materials that differed in composition, texture and land use. Derived from Mössbauer spectroscopy, broad distributions in quadrupole splittings $\left(0-2 \mathrm{~mm} \mathrm{~s}^{-1}\right)$ and magnetic hyperfine fields (35 - $53 \mathrm{~T}$ ) indicated the presence of low-crystalline ferrihydrite and even lower crystalline Fe phases in all Fe-OM co-precipitates. There was no unequivocal evidence for other Fe oxides, i.e. lepidocrocite and (nano)goethite. The Fe-OM co-precipitates contained inorganic ( $P$, sulfate, silicate, Al, As) and organic compounds (proteins, polysaccharides), which were concurrently discharged from the soils. Their content in the Fe-OM co-precipitates was controlled by their respective concentration in the soil-derived solution. On a molar basis, OC and Fe were the main components in the Fe-OM co-precipitates $(\mathrm{OC} / \mathrm{Fe}$ ratio $=0.5-2)$. The elemental composition of the Fe-OM co-precipitates was in accordance with the sequential precipitation of $\mathrm{Fe}(\mathrm{III})$ phosphates/arsenates prior to the formation of ferrihydrite. This explains decreasing Si contents in the Fe-OM co-precipitates with increasing availability of $\mathrm{P}$. With respect to constant mean quadrupole splittings and slightly decreasing mean magnetic hyperfine fields, increasing contents of $\mathrm{OC}, \mathrm{P}$ and $\mathrm{Al}$ in the Fe-OM co-precipitates did not further increase the structural disorder of the Fe polyhedra, while the crystallite interactions slightly decreased. Scanning electron microscopy and dynamic light scattering revealed the coincidental presence of variably sized aggregates and a considerable amount of Fe-OM co-precipitates, which remained dispersed in solution for months. Thus, variably composed Fe-OM co-precipitates with highly diverse aggregate sizes and comparably constant poor crystallinity can be expected after the oxidation of $\mathrm{Fe}^{2+}$ in transient, soil-derived solutions. 


\section{INTRODUCTION}

Owing to their high reactivity (Gilbert and Banfield, 2005), Fe oxides represent key reactive components in natural systems (Waychunas et al., 2005). They considerably determine the partitioning and thus the availability and mobility of nutrients (e.g. $\mathrm{PO}_{4}{ }^{3-}$, Baken et al. (2014)) and contaminants (e.g. As, Fritzsche et al. (2011)) in aquatic environments and in porous media. They are considered to exhibit a crucial role in the uptake of metals/contaminants and in the catalysis of redox processes (Frierdich et al., 2011). Fe(III) from Fe oxides also serves as substantial electron acceptor in microbial respiration under anoxic conditions (Lovley and Phillips, 1988). Thus, Fe oxides considerably affect the biogeochemical cycling of Fe (Weber et al., 2006) and of elements, which are associated with Fe oxides or are integral parts of the Fe-cycle (Li et al., 2012).

To the present day, this pronounced relevance of Fe oxides for elemental cycling in nature encouraged scientists to conduct studies on the composition and structure of Fe oxides, which precipitate in the presence of either inorganic or organic compounds. Such studies include silicate (Cismasu et al., 2014), calcium, phosphate and arsenate/arsenite in the absence and in presence of silicate (van Genuchten et al., 2014; Voegelin et al., 2010; respectively), polysaccharides (Mikutta et al., 2008), proteins (Kashyap et al., 2014) and dissolved organic matter (OM) from forest floor layers (Eusterhues et al., 2008; Mikutta et al., 2014b). While these studies provide important insights into the impact of single compounds on the Fe oxide properties, it remains unclear to what extent these findings apply to Fe oxides that precipitate in natural systems. In nature, secondary Fe oxides precipitate from solutions that contain a multitude of inorganic and organic compounds that coexist with each other. This occurs, for example, after oxidation of $\mathrm{Fe}^{2+}$ at anoxic-oxic interfaces (Murray et al., 1995), e.g. in the hyporheic zone of aquatic environments (Banfield and Zhang, 2001), in redoximorphic soils (Thompson et al., 2011) and after exfiltration of $\mathrm{Fe}^{2+}$-containing solutions (Fritzsche et al., 2006). The coexistence of organic and inorganic compounds during Fe oxide precipitation was therefore included in dedicated experimental setups, e.g. in redox-stat reactors (Schuth et al., 2015; Thompson et al., 2006), or by the use of natural solutions (Gunnars et al., 2002). However, such approaches do not acknowledge substantial soil features, i.e. relevant liquid/solid ratios and the prevalence of non-equilibrium conditions. Nonequilibrium states between the liquid, solid and gaseous phase result in a transient, i.e. permanently changing, composition of (soil) solutions with dependence on the contact time between these phases. A transient state may result in considerably altered properties of the obtained Fe oxides. For example, the degree of Fe oxide crystallinity increased in soil during redox cycles in closed redox-stat reactors (Thompson et al., 2006) while it decreased in soils under in situ conditions (Thompson et al., 2011). In open systems like in the latter study, transient 
conditions are maintained due to the variable supply of OM (topsoils) and of Si and Ti (subsoils), which inhibit the aging of Fe oxides (Thompson et al., 2011). Thus, experimental designs are required that produce sufficient amounts of co-precipitated Fe oxide phases, which are representative for nature (Thompson et al., 2011) and allow for a comprehensive characterization with complementary analytical approaches. With the present study, we intend to improve our understanding concerning the elemental composition and structure of $\mathrm{Fe}(\mathrm{III})$ minerals that precipitate from transient, soil-derived solutions after oxidation of dissolved $\mathrm{Fe}^{2+}$. Understanding the initial state of such Fe precipitates is mandatory to assess the fate of Fe in soils and its export into adjacent systems. We introduce an experimental setup that allows for the production of $\mathrm{Fe}(\mathrm{III})$ minerals with properties that are expected from precipitates at anoxic-oxic interfaces in soils. This experimental setup reproduces the transient milieu conditions characteristic of exfiltrates from soil. All reactive organic and inorganic species in the liquid phase originate solely from the soil solid phase while these phases can interact at liquid/solid ratios characteristic of waterlogged soils. Consequently, our approach acknowledges that soil-borne Fe oxides or Fe-containing silicates serve as source for aqueous $\mathrm{Fe}^{2+}$, which is then subjected to oxidation and hydrolysis. Compared to common Fe oxide synthesis, where acid solutions of Fe salts are alkalized (Schwertmann and Cornell, 2000), natural solutions with ionic Fe are therefore fundamentally different in terms of composition and ionic strength. Specifically, our experimental approach considers the presence of hydrophilic macromolecular $\mathrm{OM}$, which is characteristic of $\mathrm{pH}$ neutral, soil-derived solutions. This $\mathrm{OM}$ is the actual available fraction for interactions with the freshly precipitated Fe(III)minerals and is not necessarily represented by commonly applied humic and fulvic acids (Kleber and Johnson, 2010).

For reasons of readability, we use the term "Fe oxide" as a general synonym for all Fe(III) (oxy)(hydr)oxides. If specific Fe oxides, e.g. ferrihydrite, are discussed in this study, we refer to the mineral name.

\section{EXPERIMENTAL}

\subsection{Generation of soil-derived Fe-OM co-precipitates}

Soil columns (stainless steel, $1000 \mathrm{~cm}^{3}$, length $15.5 \mathrm{~cm}$ ) were packed with air-dried, $<2 \mathrm{~mm}$ sieved materials from two different types of topsoils. For each topsoil material, two soil columns were used (independent replicates). The soil materials originated from a humus-rich topsoil horizon (Ah) of a gleyic Fluvisol from a floodplain site (Mulde river, Saxony-Anhalt, Germany) and a plough horizon (Ap) of an agriculturally used stagnic Luvisol (IUSS Working Group., 2006). The soils differ 
in texture; Fe and organic carbon (OC) content (Table EA-1); and land use. In the following, we use $\mathrm{Ah}$ and $\mathrm{Ap}$ as acronyms for the columns filled with the respective soil material.

The columns were fed with $10^{-3} \mathrm{M} \mathrm{NaCl}$ (Merck, Germany) from bottom to top to achieve watersaturated conditions. Percolation was conducted with a peristaltic pump (Reglo Analog, Ismatec, Switzerland) at a porewater velocity of $0.25 \mathrm{~cm} \mathrm{~h}^{-1}(\mathrm{Ah})$ and $0.29 \mathrm{~cm} \mathrm{~h}^{-1}$ (Ap) with the same influent and the same flow direction. This percolation rate equals to an exchange of 0.39 (Ah) and 0.45 (Ap) pore volumes (PVs) per day. Anoxic conditions rapidly developed and prevailed in all soil columns due to the activity of autochthonous microbial communities. As a consequence, $\mathrm{Fe}^{2+}$ was released owing to the microbial Fe(III) reduction of pedogenic Fe oxides. The emergence of effluent $\mathrm{Fe}^{2+}$ was accompanied by characteristic drops in effluent redox potentials and the emergence of $\mathrm{CO}_{2}$ and inorganic carbon (IC) in the effluents of effectively IC-free soil materials (Figure EA-2). The presence of an end product $\left(\mathrm{CO}_{2}\right)$ and byproduct $\left(\mathrm{Fe}^{2+}\right)$ of microbial respiration after depletion of $\mathrm{O}_{2}$ (redox potential) are strong indicators for the microbial $\mathrm{Fe}(\mathrm{III})$ reduction in soil committed by autochthonous communities. During percolation for $>2$ PVs, the soil effluent was collected in $4(\mathrm{Ah})$ and $3(\mathrm{Ap})$ fractions. We numbered these fractions in ascending order with increasing PVs. The effluent was exposed to the ambient atmosphere ( $\mathrm{p}_{\mathrm{O} 2} \sim 21 \mathrm{kPa}$ ) as soon as discharged from the soil column. This resulted in the oxidation of discharged $\mathrm{Fe}^{2+}$ and the subsequent precipitation of $\mathrm{Fe}(\mathrm{III})$ minerals. Depending on the $\mathrm{Fe}^{2+}$ concentration, the oxidation was complete after few hours (Figure EA-3) with an expected maximum of $\sim 15 \mathrm{~h}$ in Ah_1, which contained $1.5 \mathrm{mM} \mathrm{Fe}^{2+}$. Considering the predominant anoxic conditions within the soil column and the availability of $\mathrm{O}_{2}$ outside, the column outlet equals to a static anoxic-oxic interface in this experimental design. The influent contained $10^{-3} \mathrm{M} \mathrm{NaCl}$ to control its ionic strength. Redox-active and $\mathrm{pH}$-modifying compounds were added neither to the soil materials nor to the effluent. Except for $\mathrm{Na}^{+}$and $\mathrm{Cl}^{-}$, all (in)organic species in the effluent therefore exclusively originated from the soil. Several flow interrupts were conducted to amplify the contribution of rate-limited processes at the expense of equilibrium processes (Wehrer and Totsche, 2003). For example, such flow interrupts favor the accumulation of $\mathrm{Fe}^{2+}$ in soil solution since the microbial $\mathrm{Fe}$ (III) reduction is in nonequilibrium with respect to the mean residence time of the solution in the soil (Ah: $\sim 3 \mathrm{~d}, \mathrm{Ap}: \sim 2 \mathrm{~d}$ ). More details on this experimental approach and a schedule of the sampled effluent fractions are given in Figure EA-4. All soil column experiments were conducted at $295 \pm 2 \mathrm{~K}$.

\subsection{Effluent filtration, dialysis and drying}

Filtration was conducted with polyethersulfone filters $(0.45 \mu \mathrm{m}$ Acrodisc, Pall Scientific, USA). Effluent dialysis (1000 kDa; Spectra/Por Float-A-Lyzer G2, Spectrum Laboratories, USA) against 
ultrapure water (Elix + MilliQ, Millipore, USA) was necessary to avoid precipitation of salts during effluent drying. This is mandatory for scanning electron microscopy (SEM), Fourier-transform infrared (FTIR) spectroscopy and X-ray diffractometry (XRD). Except for SEM and elemental analysis, the dialyzed effluent was freeze-dried (Alpha 1-4 LSC, Christ, Germany).

\subsection{Mössbauer spectroscopy, SEM, FTIR spectroscopy, positive matrix factorization and elemental composition of the effluent precipitates}

${ }^{57} \mathrm{Fe}$ Mössbauer spectroscopy was conducted at the Centre of Applied Geosciences Tübingen (Eberhard-Karls-University, Germany). The freeze-dried precipitates from each unfiltered dialyzed effluent fraction were studied at $77 \mathrm{~K}$ and $5 \mathrm{~K}$ using a closed cycle cryostat (Janis, USA). Mössbauer spectra were recorded in transmission geometry (Wissel, Germany) using a triangular velocity waveform and a source of ${ }^{57} \mathrm{Co}$ in $\mathrm{Rh}$ matrix. The spectra were calibrated against a measurement of $\alpha-\mathrm{Fe}(0)$ foil at room temperature and were evaluated with the Recoil software package (University of Ottawa, Canada) using Voigt-based fitting methods. We chose a single site model with two Gaussian components to reflect the spectral asymmetries in the Mössbauer spectra. See EA-13 for further details of the fitting approach.

For SEM, $10 \mu$ l of unfiltered dialyzed effluent were air-dried on a Si wafer equipped with a $4 \times 4 \mathrm{Cu}$ grid (edge length: $500 \mu \mathrm{m}$ ). Analysis was conducted with an ULTRA PLUS field emission scanning electron microscope (Zeiss, Germany). Aggregate areas were calculated with the software ImageJ (V. 1.47) from secondary electron (SE) images, which were recorded on 3 random grid sectors. Due to limitations in SE image resolution, particle areas $<80 \mathrm{~nm}^{2}$ were excluded from quantification. For spheres, this equals to a diameter of $\sim 10 \mathrm{~nm}$.

FTIR spectra were recorded using a Nicolet iS10 spectrometer (Thermo Fisher Scientific, Germany). In transmission mode, the freeze-dried precipitates of each unfiltered dialyzed effluent fraction were mortared and mixed with $\mathrm{KBr}$ (FTIR spectroscopy grade, Merck, Germany) at a volume ratio of $\sim 1: 200$ and pressed to pellets. The pellets were measured between 4000 and 400 $\mathrm{cm}^{-1}$ with 16 scans per spectrum at a resolution of $4 \mathrm{~cm}^{-1}$. The spectra were baseline corrected and normalized to maximum intensity.

Filters, which were used for the filtration of dialyzed effluent fractions, were dried in the dark at room temperature and investigated in attenuated total reflection (ATR)-mode between 4000 and $650 \mathrm{~cm}^{-1}$ with 16 scans per spectrum at a resolution of $4 \mathrm{~cm}^{-1}$. The filter cake was considered to exclusively consist of the Fe-OM co-precipitates. Free $\mathrm{OM}_{>0.45 \mu \mathrm{m}}$ is excluded since $\mathrm{OC}_{>0.45 \mu \mathrm{m}}$ was absent in those samples, in which the entire effluent Fe passed the $0.45 \mu \mathrm{m}$-filters (Figure EA-5). No post-processing was applied to the ATR-FTIR spectra in order to maintain all features for factor 
analysis, which was carried out with positive matrix factorization (PMF) using an alternating nonnegative least-squares approach (Kim and Park, 2008). Two components were required to explain 99.3\% (Ah-derived samples) and 99.6\% (Ap-derived samples) of the variance in the measured spectra. The uncertainty of the component shapes was quantified with the $95 \%$ confidence interval at each wavenumber. Uniqueness of the PMF solution was emphasized by identical results despite random initialization (Figure EA-6). If not stated otherwise, the bands in FTIR spectra were interpreted according to Socrates (2001).

The elemental composition ( $\mathrm{Fe}, \mathrm{Al}, \mathrm{As}, \mathrm{Ca}, \mathrm{P}, \mathrm{S}, \mathrm{Si}$ ) of the precipitates was determined with inductively coupled plasma optical emission spectroscopy (ICP-OES; Varian 725, Varian, Germany) in acidified samples. Non-purgeable organic carbon (NPOC) was measured by sample combustion after acidification and purging with C-free synthetic air (Multi N/C 2100, Analytik Jena, Germany). Although we chose the largest molecular weight cutoff available for dialysis tubes, the removal of OM, which was not associated with the effluent precipitates, was incomplete in unfiltered effluent. Thus, the elemental composition of the Fe precipitates was assessed on basis of the composition of the filter cake (Figure EA-5). The concentration of elements in the filter cakes $(>0.45 \mu \mathrm{m})$ was calculated as difference between the filtered $(<0.45 \mu \mathrm{m})$ and unfiltered fraction of the dialyzed effluent.

\section{4. $\mathrm{pH}$, effluent composition, hydrodynamic diameter $\left(\mathrm{d}_{H}\right)$, Zeta potential $\left(U_{E}\right)$}

These parameters were assessed in non-dialyzed effluent fractions. Effluent $\mathrm{pH}$ was analyzed potentiometrically in unfiltered samples (Sentix 41; WTW, Germany). Effluent concentrations of Fe, Al, As, Ca, P, S, Si and NPOC were measured with ICP-OES and sample combustion, respectively (refer to 2.3.). Colloid $d_{H}$ was analyzed in unfiltered effluent fractions by dynamic light scattering (DLS) in backscattering mode (Nano ZS, Malvern Instruments, UK). The interpretation of $d_{H}$ is based on the intensity of light scattering and was derived from fitting a multiple exponential (CONTIN) to the autocorrelation function. Colloid $U_{E}$ was calculated with the Smoluchowski approximation from the electrophoretic mobility of the particles in unfiltered effluent (Nano ZS).

\subsection{Fe-OM co-precipitate-free control treatment}

A control treatment free of Fe-OM co-precipitates was included to assess the interferences of potentially coexistent particulate constituents in the soil effluent (i.e. biocolloids, silicates). This control was obtained from the same soil columns and conditions as described above, except for the instant acidification of the effluent upon discharge. The effluent was subsequently dialyzed (100-500 Da, Spectra/Por Biotech CE, Spectrum Laboratories). This treatment removed the 
majority of $\mathrm{Fe}^{2+}$ from the effluent before its oxidation could occur. Due to dialysis against ultrapure water from the same source $(\mathrm{pH} \sim 5.5$ in equilibrium with air), initial differences in the effluent $\mathrm{pH}$ of non-acidified and acidified effluent fractions were effectively equalized. The effluent acidification does therefore not contradict the comparison of respective X-ray diffractograms and FTIR spectra. Due to this treatment, the effluent was effectively free of Fe-OM co-precipitates and contained macromolecular OM only (EA-7).

\section{RESULTS}

\subsection{Effluent composition}

The composition of the soil effluent changed continuously with increasing pore volumes (PVs), pointing to the transient conditions. Besides $\mathrm{Ca}, \mathrm{Mg}, \mathrm{Na}, \mathrm{K}, \mathrm{Mn}$ and $\mathrm{Ba}$, the effluents from both soils contained OC, Fe, Si, P, and S (Figure EA-8 (Ah) and Figure EA-9 (Ap)). The Ah-derived effluent contained $\mathrm{Al}$ and $\mathrm{As}$, which were below the detection limits in the Ap-derived effluent $(\mathrm{Al}<$ $0.01 \mathrm{mg} \mathrm{L}^{-1}$; As $<0.04 \mathrm{mg} \mathrm{L}^{-1}$ ). Arsenic accumulated in the soil of the floodplain site due to periodic flooding with As-containing water from the Mulde river (Brandt, 2003). Except for Al and P, total concentrations of all elements decreased in the effluent with increasing PVs (Figure EA-8 and EA9). This is also reflected by decreasing electric conductivities (Table 1). Besides absolute concentrations, the concentrations of effluent compounds relative to effluent $\mathrm{Fe}$ also shifted continuously (X-axis in Figure 1). This was not observed for As, which points to the coupled mobilization of $\mathrm{Fe}$ and As from Ah, e.g. due to the reductive dissolution of As-bearing pedogenic Fe oxides. The concentration of all elements relative to Fe increased with increasing PVs except for As and $\mathrm{Ca}$ (Figure 1).

\subsection{Structural characterization of the Fe-OM co-precipitates}

After oxidation of $\mathrm{Fe}^{2+}$, which was the initial redox state of discharged Fe (Figure EA-2), Fe-rich particulate matter precipitated from the effluent of both topsoils at circum-neutral pH (Table 1). This resulted in an orange-reddish color of the effluent (Figure EA-10). After dialysis, OC, Fe, As (Ahderived effluent only), P, Si, S and Ca remained in the effluent (Ah: Figure EA-11; Ap: Figure EA12 ), suggesting that the precipitates consist of these elements. On a molar basis, OC and Fe were the main constituents of these precipitates, which are henceforth referred to as Fe-OM coprecipitates.

Mössbauer spectra showed (super)paramagnetic Fe-OM co-precipitates at $77 \mathrm{~K}$ (doublets) and magnetically ordered Fe-OM co-precipitates at $5 \mathrm{~K}$ (sextets, Figure EA-13). Two Gaussian components were required to account for the asymmetry in the doublets and sextets, with the 
exception of the $5 \mathrm{~K}$-spectrum of Ap_1 (one component sufficient; Table 2). This may represent a real structural difference or it may be merely an artefact of a poor signal-to-noise ratio in the spectrum of this sample (Figure EA-13). The replicate did not show the same behavior and therefore suggests that the latter is more likely. In the $77 \mathrm{~K}$-Mössbauer spectra, the two components were weighted roughly in equal measure. No consistent changes were observed in their electric quadrupole splitting $\left(\Delta \mathrm{E}_{\mathrm{Q}_{-} \mathrm{C} 1} \sim 0.7 \mathrm{~mm} \mathrm{~s}^{-1} ; \Delta \mathrm{E}_{\mathrm{Q}_{-} \mathrm{C} 2} \sim 1.1 \mathrm{~mm} \mathrm{\textrm {s } ^ { - 1 }}\right)$ and their weighting factor with respect to the precipitates sampled at increasing PVs (Table 2). Consequently, the positions and widths of $\Delta \mathrm{E}_{\mathrm{Q}}$-distributions, ranging from $\Delta \mathrm{E}_{\mathrm{Q}}=0-2 \mathrm{~mm} \mathrm{~s}{ }^{-1}$ (Figure $2 \mathrm{~A}, \mathrm{C}$ ), were similar for all Fe-OM co-precipitates, although they precipitated from differently composed Ahderived solutions (refer to 3.1.). In comparison to the Fe-OM co-precipitates from Ah-derived solutions, a considerable shift to lower $\Delta \mathrm{E}_{\mathrm{Q}}$ values was observed for Fe-OM co-precipitates from an Ap-derived solution (Figure 2A). Again, this may therefore be an artefact of the poor signal-to-noise ratio in the spectra obtained from this sample. This is supported by our observation that this considerable $\Delta \mathrm{E}_{\mathrm{Q}}$-shift was not reproduced by the replicate (Figure $2 \mathrm{C}$ ). Nevertheless, the Fe-OM co-precipitates from Ap-derived solutions reproducibly exhibited lower average $\Delta \mathrm{E}_{\mathrm{Q}}\left(0.82 \mathrm{~mm} \mathrm{~s}^{-1}\right)$ than the Fe-OM co-precipitates from the Ah-derived solutions ( $0.88 \mathrm{~mm} \mathrm{~s}^{-1}$; Table 2$)$. In the fits of the $5 \mathrm{~K}$-Mössbauer spectra, the component assigned to the higher magnetic hyperfine fields $\left(\mathrm{B}_{\mathrm{hf}}\right)$ was more pronounced than the component assigned to the lower $\mathrm{B}_{\mathrm{hf}}$, which resulted in negatively skewed distributions of $\mathrm{B}_{\mathrm{hf}}$ (Table 2, Figure 2B,D). These distributions covered a range of $\sim 35 \mathrm{~T}$ to $\sim 53 \mathrm{~T}$. In contrast to $\Delta \mathrm{E}_{\mathrm{Q}}$, the $\mathrm{B}_{\mathrm{hf}}$ distributions of the Fe-OM co-precipitates from Ah-derived solutions shifted systematically to lower values with increasing PVs. This is reflected by the reproducible decrease in average $B_{h f}$ from $\sim 46 \mathrm{~T}\left(\mathrm{Ah} \_1\right)$ to $\sim 45 \mathrm{~T}$ (Ah_4; Table 2). However, the $\mathrm{B}_{\mathrm{hf}}$-decrease by $\sim 1 \mathrm{~T}$ was clearly below the average standard deviations of the $\mathrm{B}_{\mathrm{hf}}$-distributions ( $>3$ $\mathrm{T}$ ), which narrows the relevance of this decrease considering the broadly distributed magnetic properties of the Fe-OM co-precipitates. In agreement with the clearly different $\Delta \mathrm{E}_{\mathrm{Q}}$-distribution of an Ap-derived Fe-OM co-precipitate (Figure $1 \mathrm{~A}$ ), the $\mathrm{B}_{\mathrm{hf}}$-distribution of this particular sample was also clearly different from the remaining samples. The distribution was Gaussian shaped and covered considerably higher $\mathrm{B}_{\mathrm{hf}}$ up to $58 \mathrm{~T}$ (Figure $2 \mathrm{~B}$ ). In agreement with the $\Delta \mathrm{E}_{\mathrm{Q}}$-distribution, this observation was not reproduced by the replicate (Figure 2D), and we point out the poor signal-tonoise ratio again (Figure EA-13). Nevertheless, the average $B_{h f}$ of both Ap-derived Fe-OM coprecipitates were higher than those of the Ah-derived Fe-OM co-precipitates (46.3 T vs. 45 - 46 T, respectively; Table 2).

Transmission-FTIR spectra of freeze-dried material from all dialyzed effluents revealed the presence of ferrihydrite by respective bands at $460 \mathrm{~cm}^{-1}$ and $650 \mathrm{~cm}^{-1}$ (Figure 3 , Cornell and Schwertmann (2003)). The latter band was not present in the OM-containing effluent, in which the 
Fe-OM co-precipitates were absent (EA-7). This emphasizes the contribution of ferrihydrite to the IR absorption of material that contained the effluent Fe-OM co-precipitates. Bands characteristic of lepidocrocite and goethite were not observed in the FTIR spectra (Figure 3). X-ray diffractometry indicated the predominance of 2-line ferrihydrite in the Fe-OM co-precipitates from Ah-derived effluent, but contributions of amorphous $\mathrm{Fe}(\mathrm{III})$ arsenates and -phosphates cannot be ruled out (Figure EA-14A,B) Calcite was observed in the very first effluent fraction of Ap after onset of percolation (Ap_1, Figure EA-14C). Although not shown by the diffractogram of effluent material from the replicate soil column, we assume the presence of calcite in Ap_1 of both soil columns due to the high amount of $\mathrm{Ca}_{>0.45}$. Calcite formation in Ap_1 was favored owing to comparably high concentrations of $\mathrm{Ca}$, inorganic carbon and high $\mathrm{pH}$ in this particular effluent fraction (Figure EA14).

Considerable amounts of the effluent Fe-OM co-precipitates remained dispersed in solution for months. This was particularly pronounced in the effluent after percolation of $>1$ PV (Ah_3+4; Figure EA-10). Except for Ap_1, $\sim 10-50 \%$ of $\mathrm{Fe}_{\text {total }}$ passed the $0.45 \mu \mathrm{m}$-filter cutoff (Table 1). Dynamic light scattering (DLS) revealed the presence of effluent colloids with hydrodynamic diameters $\left(d_{H}\right)<0.45 \mu$ m, which points to colloidal Fe-OM co-precipitates. The mean $d_{H}$ varied in response to the transient effluent composition and decreased with increasing PVs (Table 1). This is confirmed by secondary electron (SE) images from these precipitates (Figure 4). There, the aggregate shapes indicate that they consist of several smaller particles. SE image analysis revealed broadly distributed aggregate sizes in each effluent fraction with decreasing average and maximum values with increasing PVs (Figure 4D). This agrees with the results from DLS analysis (Table 1). The SE images also revealed a high abundance of very small aggregates $(<20 \mathrm{~nm})$ in all effluent fractions, independent of the extent in aggregation (Figure 4D).

\subsection{Elemental composition of the Fe-OM co-precipitates}

The transient soil effluent composition (see section 3.1.) induced a variable elemental composition of the Fe-OM co-precipitates that formed in this solution (Figure 1). Generally, increasing element/Fe ratios in the effluent resulted in higher element/Fe ratios in the Fe-OM co-precipitates. As an exception, increased relative concentrations of effluent $\mathrm{Si}$ resulted in decreased relative $\mathrm{Si}$ contents in the Fe-OM co-precipitates (Figure 1D). The entire effluent $P$ and $A l$ was associated with the Fe-OM co-precipitates (Figure 1C,F). In contrast, only parts of effluent $\mathrm{OC}$ and $S$ were associated with the Fe-OM co-precipitates (Figure 1A,E). Compared to P, Al, OC, S and As, high molar ratios of effluent Si/Fe (0.2 - 1.0) resulted in comparably low Si/Fe ratios in the Fe-OM coprecipitates (<0.06; Figure 1D). This was even more pronounced for $\mathrm{Ca}$, which was sparse in the 
Fe-OM co-precipitates $(\mathrm{Ca} / \mathrm{Fe}<0.03$; Figure $1 \mathrm{G})$ although highly abundant in the effluent $(\mathrm{Ca} / \mathrm{Fe}=$ 0.5 - 4.2). Similar to As, the effluent $\mathrm{Ca} / \mathrm{Fe}$ remained comparably constant with increasing $\mathrm{PVs}$, which points to a coupled mobilization of $\mathrm{Ca}$ and $\mathrm{Fe}^{2+}$. Nevertheless, the $\mathrm{Ca} / \mathrm{Fe}$ ratios in the $\mathrm{Fe}-\mathrm{OM}$ co-precipitates increased with increasing PVs. Concerning the mass, in particular OC (90 - $463 \mathrm{mg}$ $\left.(\mathrm{g} \mathrm{Fe})^{-1}\right)$, As $\left(\sim 90 \mathrm{mg}\left(\mathrm{g} \mathrm{Fe}^{-1}\right)\right.$ and $\mathrm{P}\left(7-148 \mathrm{mg}(\mathrm{g} \mathrm{Fe})^{-1}\right)$ were the most prominent elements associated with the effluent Fe-OM co-precipitates (Table EA-16). Despite comparable OC/Fe ratios in the effluent of both soil materials, OC contents in the Fe-OM co-precipitates from Apderived effluent were clearly lower than in the Fe-OM co-precipitates from Ah-derived effluent (Figure 1A). Neither As nor Al were associated in detectable amounts with the Fe-OM coprecipitates from Ap-derived effluents since these elements were also below their detection limits in the corresponding effluent (Figure 1B,F).

In the transmission-FTIR spectra of freeze-dried material from dialyzed, Ah-derived effluents, the band at $825 \mathrm{~cm}^{-1}$ points to ferrihydrite-adsorbed As(V) (Voegelin and Hug, 2003) (Figure 3A). In agreement with the nearly constant molar As/Fe ratio in the Fe-OM co-precipitates from Ah-derived effluent (Figure 1B), the contribution of this band was similar in all corresponding FTIR spectra. Consequently, this band was absent in the FTIR spectra of material from Ap-derived effluents, which did not contain detectable As concentrations (Figure 3B). The presence of non-polymerized $\mathrm{Si}$, which is associated with the Fe-OM co-precipitates, is indicated by Si-O-Fe bonds, which cause a broad absorption between $900 \mathrm{~cm}^{-1}$ and $1000 \mathrm{~cm}^{-1}$ (Figure $3 \mathrm{~A}, 930 \mathrm{~cm}^{-1}$; Carlson and Schwertmann (1981); Doelsch et al. (2001)). This band may be indicative for monomeric silicate, which bonds to Fe polymers and ferrihydrite particles at Si contents as low as observed in our study ( 5 mol\%; Cismasu et al. (2014)). The band vanished in the spectra of Ah_3+4, in which the Fe-OM co-precipitates contained the lowest Si content (Figure 1D). The Si-O-Fe-bond disappears at a molar Si/Fe ratio $<0.03-0.04$. Oligomeric Si species, which develop at molar $\mathrm{Si} / \mathrm{Fe}$ ratios $>0.01$ and $\mathrm{pH}=3$ (Swedlund et al., 2009) could not be traced due to superposing bands from adsorbed sulfate. Although the molar Si/Fe ratio was 0.02 - 0.06 in our study, we assume the predominance of monomeric Si species owing to the effluent $\mathrm{pH} \sim 7.5$ (Table 1), which effectively inhibits Si polymerization at the Fe oxide surface (Doelsch et al., 2001). For the Fe-OM coprecipitates from Ap-derived effluent, the Si-O-Fe band was only indicated in the spectrum of material with the highest Si/Fe ratio (replicate Ap_1). The local absorption maximum at $1042 \mathrm{~cm}^{-1}$ is mainly induced by polysaccharides (C-O-C stretch, $\mathrm{C}-\mathrm{OH}$ stretch), which is also predominant in the Fe-OM co-precipitate-free control with effluent OM (EA-7). The shoulders at $1100 \mathrm{~cm}^{-1}$ and 975 $\mathrm{cm}^{-1}$ in the spectra of the Fe-OM co-precipitate-containing material are caused by adsorbed sulfate (Peak et al. (1999); Figure 3). Its contribution increased with increasing relative $S$ content in the Fe-OM co-precipitates from Ah-derived effluents, i.e. with ascendant fraction number (Figure 1E). 
Detection of adsorbed phosphate (1088, 1021 and $952 \mathrm{~cm}^{-1}$; Arai and Sparks (2001)) was impeded by superposing bands of effluent $\mathrm{OM}$ and the absence of distinct shoulders (Figure 3). This was likely related to the freeze-drying of the Fe-OM co-precipitates, which results in a rather broad band at $1036 \mathrm{~cm}^{-1}$ induced by adsorbed phosphate (Wang et al., 2013). Adsorbed As, Si, and sulfate could not be traced in spectra of the Fe-OM co-precipitate-free controls, which points to the interaction of these compounds with the Fe-OM co-precipitates. We are aware that the cited studies rely on ATR-FTIR spectra, which might impair applicability on transmission-FTIR spectra. However, all features from transmission spectra were also present in corresponding ATR-FTIR spectra (Figure EA-17).

\subsection{OM composition in the Fe-OM co-precipitates}

FTIR spectra from freeze-dried, dialyzed soil effluent fractions could not be used for the characterization of Fe-associated $\mathrm{OM}$ due to interferences by free particulate effluent $\mathrm{OM}$ that could not be removed from the effluent. For this reason, ATR-FTIR spectra of filter cakes were used to distinguish between free effluent $\mathrm{OM}$ and $\mathrm{OM}$ in the Fe-OM co-precipitates. We assume the filter cakes to consist solely of Fe-OM co-precipitates, which is indicated by the absence of $\mathrm{OC}_{>0.45 \mu \mathrm{m}}$ in samples free of $\mathrm{Fe}_{>0.45 \mu \mathrm{m}}$ (Figure EA-5). Positive matrix factorization (PMF) revealed that two components were required to reconstructed the contribution of the filter material and the Fe-OM co-precipitates to the measured ATR-FTIR spectra (Figure 5A,D). Indicated by the congruence between the pure filter spectrum and component 1 (Figure EA-18), PMF was able to separate filter-induced bands from Fe-OM co-precipitate-induced bands in the ATR-FTIR spectra. The PMF component specifying the latter (component 2, Figure 5B,E) exhibited local absorption maxima at $1630 \mathrm{~cm}^{-1}$ (amide I and H-O-H deformation), $1555 \mathrm{~cm}^{-1}$ (amide II), $1400 \mathrm{~cm}^{-1}$ (sym. $\mathrm{COO}^{-}$stretch) and $1042 \mathrm{~cm}^{-1}$ (C-O-C stretch, C-OH stretch in polysaccharides; adsorbed phosphate (Wang et al., 2013)). A tailing at $1600 \mathrm{~cm}^{-1}$ (asym. COO- stretch) and a shoulder at $\sim 1440 \mathrm{~cm}^{-1}\left(\mathrm{CH}_{3}\right.$ deformation, $-\mathrm{CH}_{2}$ - scissoring) were also pronounced. Consequently, the $\mathrm{OM}$ in the Fe-OM co-precipitates was composed of proteins, carboxyls and polysaccharides.

Comparing measured spectra with reference spectra is the general idea of differential spectra and discloses features that are unrevealed in whole spectra (Dryer et al., 2008). In our study, component 2 from PMF can be understood as average ATR-FTIR spectrum of all Fe-OM coprecipitates from either Ah-derived or Ap-derived effluent. This PMF component was used as reference spectrum, to which all measured spectra from the corresponding soil material were referred. The differences between reference and measured spectrum was quantified as residual spectrum (Figure 5C,F). In the PMF assay with spectra of Fe-OM co-precipitates from Ah-derived 
effluent, component 2 exhibited locally enlarged confidence intervals (Figure 5B). These were induced by the variable contents of (in)organic compounds in the Fe-OM co-precipitates. Following Lambert-Beer law (Davis et al., 1999), positive residuals between the measured vs. the reference spectrum are obtained if the content of the respective IR-active compound exceeds its mean content. With increasing ratios of $\mathrm{OC} / \mathrm{Fe}$ in the Fe-OM co-precipitates from Ah-derived effluents (with ascendant effluent fraction number; Figure $1 \mathrm{~A}$ ), the residuals consequently shifted from negative to positive values at all wavenumbers related to $\mathrm{OM}$ (Figure $5 \mathrm{C}$ ). This was inversed for $\mathrm{Si}-\mathrm{O}-\mathrm{Fe}\left(930 \mathrm{~cm}^{-1}\right.$; Figure $\left.5 \mathrm{C}\right)$ since the Si content in the Fe-OM co-precipitates decreased with increasing PVs. In comparison to Ah, component 2 from the PMF-assay with Ap-derived Fe-OM co-precipitates exhibited smaller confidence intervals. This points to rather constant OM contents in these Fe-OM co-precipitates, which agrees with their comparably invariable $\mathrm{OC} / \mathrm{Fe}$ ratio (Figure 1A). Different polysaccharide contents in the Fe-OM co-precipitates from the effluents of the two replicate Ap-soil columns were indicated by solely positive residuals between $1100-950 \mathrm{~cm}^{-1}$ for one column (Figure 5F) and solely negative residuals for the replicate column (Figure EA-21F). With respect to the similar $\mathrm{P}$ contents in these Fe-OM co-precipitates (Figure 1C), this observation also confirms that the broad band at $\sim 1040 \mathrm{~cm}^{-1}$ cannot be induced by adsorbed phosphate solely.

\section{DISCUSSION}

\subsection{Elemental composition of the Fe-OM co-precipitates at transient conditions}

The relevance of non-equilibrium conditions in soils is emphasized by the observable distinct changes in concentrations of effluent (in)organic compounds with dependence on the contact time between the liquid and solid phase. Flow interruptions, which increase the contact time, induced changes in effluent concentrations with respect to their total values and to their values relative to effluent Fe. Consequently, the Fe-OM co-precipitates precipitated from solutions with permanently variable amounts of (in)organic compounds. In accordance to the basic concept of liquid-solid distribution, higher relative effluent concentrations of $\mathrm{P}, \mathrm{Al}, \mathrm{OC}$, and $\mathrm{S}$ mostly resulted in higher relative contents in the Fe-OM co-precipitates. Notwithstanding, shifts in Si and Ca contents in the Fe-OM co-precipitates were not correlated to corresponding shifts in the effluent concentrations of $\mathrm{Si}$ and $\mathrm{Ca}$ relative to Fe. We explain this observation as follows: Depending on the elemental composition of the precipitate, selected compounds from solution are consumed during the precipitation. Such compounds are less available or exhausted during the formation of subsequent precipitates, resulting in a temporal sequence of characteristic precipitate compositions. After Fe $\mathrm{Fe}^{2+}$ oxidation in pH-neutral solutions, Voegelin et al. (2010) observed the preferential precipitation of $\mathrm{Fe}(\mathrm{III})$ phosphates as long as phosphate was available and the formation of ferrihydrite as long as 
silicate was available. Finally, lepidocrocite formed when silicate was sufficiently depleted. Likewise, $\mathrm{Fe}(\mathrm{III})$ arsenates preferentially precipitated from oxidized $\mathrm{Fe}^{2+}$-solutions as long as arsenate was available, while lepidocrocite formed in the absence of arsenate and phosphate (van Genuchten et al., 2014). The shifts in elemental composition of the Fe-OM co-precipitates, which were observed in the different effluent fractions, suggest that such a sequential precipitation also applies to the soil-derived solutions of our study. The quantitative association of $P$ and As with the Fe-OM co-precipitates can be explained with the preferential formation of phosphate/arsenatelinked $\mathrm{Fe}$ (III) oligomers until $\mathrm{P}$ and As are depleted from the effluent. In contrast to the ratios of effluent $\mathrm{As} / \mathrm{Fe}$, the ratios of effluent P/Fe increased with increasing PVs. Assuming constant $\mathrm{P}$ contents in the phosphate-linked Fe(III) oligomers, a greater proportion of effluent Fe is present as $\mathrm{Fe}(\mathrm{III})$ phosphate in the later effluent fractions compared to the early effluent fractions. With increasing molar ratios of effluent $\mathrm{P} / \mathrm{Fe}$, a lower proportion of Fe polyhedra was therefore available to interact with effluent silicate. Thus, increasing $\mathrm{P} / \mathrm{Fe}$ in the $\mathrm{Fe}-\mathrm{OM}$ co-precipitates resulted in decreased $\mathrm{Si} / \mathrm{Fe}$ in the Fe-OM co-precipitates. This is particularly pronounced if the Ah- and Apsoil columns are considered separately (Figure 1I). The exhaustion of available Fe for interaction with silicate is also indicated by $\mathrm{Si} / \mathrm{Fe}$ ratios in the Fe-OM co-precipitates, which continuously diverge from the 1:1 correlation to effluent Si/Fe with increasing PVs, i.e. with increasing effluent $\mathrm{P} / \mathrm{Fe}$. This exhaustion of available Fe polyhedra explains the decreasing Si/Fe in the Fe-OM coprecipitates with increasing effluent $\mathrm{Si} / \mathrm{Fe}$ ratios. We exclude a hypothetic interference of $\mathrm{Al}$ on these $\mathrm{P} / \mathrm{Fe}$ vs. Si/Fe interdependencies, although $\mathrm{Al} / \mathrm{Fe}$ ratios in the $\mathrm{Fe}-\mathrm{OM}$ co-precipitates also increased continuously with increasing PVs (similar to P/Fe; Figure 1F). This is based on the fact that the mentioned P/Fe vs. Si/Fe-correlation also applied to the Ap-derived effluents, in which Al was not detected (Figure 1F). Voegelin et al. (2010) also observed the bridging of $\mathrm{Fe}(\mathrm{III})$ phosphate oligomers by $\mathrm{Ca}^{2+}$, which was confirmed by van Genuchten et al. (2014), who also revealed that this effect was existent but less pronounced for $\mathrm{Fe}(\mathrm{III})$-arsenates. Since As/Fe was constant in the Fe-OM co-precipitates, one would consequently expect increasing $\mathrm{Ca} / \mathrm{Fe}$ in the $\mathrm{Fe}$ OM co-precipitates with increasing P/Fe, i.e. with increasing PVs. This was observed in our study, except for one soil column (Ah_replicate; Figure $1 \mathrm{H}$ ). Nevertheless, a maximum P/Fe ratio of the Fe-OM co-precipitates was accompanied by a maximum $\mathrm{Ca} / \mathrm{Fe}$ ratio in each treatment, although the availability of Ca was comparably constant in all effluent fractions (effluent $\mathrm{Ca} / \mathrm{Fe}$ in Figure $1 \mathrm{G}$ ). It is worth mentioning that the shifts in the average elemental composition of Fe-OM coprecipitates from OM-containing soil-derived solutions agree with the expected shifts that arise from the sequential formation of variable Fe-rich precipitates, which was proposed for pure inorganic systems (van Genuchten et al., 2014; Voegelin et al., 2010). It is known that e.g. the $\mathrm{Fe}^{3+}$-nucleation is favored at protein micelle surfaces and results in the formation of disordered 
ferrihydrite (Kashyap et al., 2014). Nevertheless, the polymerization of Fe polyhedra, which are linked via phosphate, arsenate and $\mathrm{Ca}$, is relevant in soil solutions, which contain organic species such as proteins.

\subsection{Composition of OM in the Fe-OM co-precipitates at transient conditions}

In our study, the Fe-OM co-precipitates from oxidized, soil-derived $\mathrm{Fe}^{2+}$-containing solutions are associated with proteins and polysaccharides. This agrees with observations of Fe-OM-coprecipitates in streambeds (ThomasArrigo et al., 2014) and in soils, in which poorly crystalline Fe minerals significantly correlated with concentrations of aliphatic and amide C (Mikutta et al., 2009). The proteins and polysaccharides very likely originated from microbial extracellular polymeric substances (EPS; Omoike et al. (2004)). Thus, microbial Fe(III) reduction, which contributed to the microbial activity in the experimental setup, is a source for OM that is associated with the Fe-OM co-precipitates. Due to their hydrophilic character, proteins and polysaccharides represent a prominent fraction of $\mathrm{OM}$ in the aqueous phase and are therefore available for interaction with the Fe-rich precipitates. Comparing both topsoil materials, the Fe-associated OM in Ap-derived effluent was enriched in polysaccharides while the Fe-associated OM in Ah-derived effluent contained more proteins. This is indicated by corresponding IR absorption bands in the respective PMF components (Figure 5B,E; Figure EA-6B). The higher OC content in the Fe-OM coprecipitates from Ah-derived effluents despite similar effluent $\mathrm{OC} / \mathrm{Fe}$ ratios and the higher proportion of proteins in this Fh-associated OM points to a higher availability of proteins in the Ahderived effluent compared to Ap-derived effluent. Higher protein concentrations in Ah-derived effluent agree with the more intensive and sustained microbial Fe(III) reduction in Ah. This is likely linked with the higher absolute and relative content of low crystalline Fe oxides in Ah compared to Ap (Table EA-1). However, while the transient effluent composition resulted in variable OM content in the Fe-OM co-precipitates, its composition was rather static. This is indicated by the fact that only one PMF component was required to sufficiently address the IR absorption of all effluent FeOM co-precipitates from one soil material. This observation can be explained either by an invariable composition of effluent $\mathrm{OM}$ or by the selective uptake of a permanently available OM fraction by the Fe-OM co-precipitates. According to the literature, we expect a rather variable composition of soil effluent OM (Weigand and Totsche, 1998). Furthermore, OM fractionation, e.g. due to association with ferrihydrite has been described previously (Eusterhues et al., 2011), rendering this scenario more likely. For more substantial statements, further investigations are required, which explicitly acknowledge the prevalence of transient conditions in soils and other natural systems. 
Concerning the Ah-derived effluents, the close association between $\mathrm{OC}$ and $\mathrm{S}$ was indicated by the similar removal from the effluent during dialysis (Figure EA-11C,D) and the comparable distribution of free vs. Fe-associated $O C$ and $S$ (Figure 1A,E). We therefore suppose the association of organic $S$ with the Fe-OM co-precipitates besides sulfate-S. This association agrees with mainly organically bound $S$ in topsoil horizons (Prietzel et al., 2013) and high S content in proteins that preferably adsorb on goethite (Liu et al., 2013).

\subsection{Structural changes in the Fe-OM co-precipitates at transient conditions}

The constant center shifts in the Mössbauer spectra of all Fe-OM co-precipitates $\left(\delta \sim 0.48 \mathrm{~mm} \mathrm{~s}^{-1}\right.$ at $77 \mathrm{~K}$; Table 1) indicate a constant Fe valence despite their different elemental composition (Cornell and Schwertmann, 2003). Because the source was always at room temperature while the absorber was cooled, the center shift values at temperatures below room temperature reflect the sum of the center shift and the temperature dependent second order Doppler shift. At room temperature, a value of $\delta=0.36 \mathrm{~mm} \mathrm{~s}^{-1}$ was obtained for the Ap1_replicate $\left(0.47 \mathrm{~mm} \mathrm{~s}^{-1}\right.$ at $\left.77 \mathrm{~K}\right)$ and is assumed for the remaining Fe-OM co-precipitates. This value is in accordance with the exclusive presence of $\mathrm{Fe}$ (III) (e.g. Gütlich and Schröder (2012)) and falls into the range of reported low-crystalline Fe oxides, which reacted with inorganic (e.g. As; Rancourt et al. (2001)) and organic compounds (Eusterhues et al., 2008; Mikutta et al., 2008).

Two components with identical $\delta$ but variable electric quadrupole splittings $\left(\Delta \mathrm{E}_{\mathrm{Q}}\right)$ were applied to fit the asymmetric doublets in the $77 \mathrm{~K}$-Mössbauer spectra. This implies the coexistence of a range of $\Delta \mathrm{E}_{\mathrm{Q}}$ in each Fe-OM co-precipitate in accordance with polyhedral Fe coordination to accommodate a large variety of cations. The probability distributions of $\Delta \mathrm{E}_{\mathrm{Q}}$ were positively skewed with most probable $\Delta \mathrm{E}_{\mathrm{Q}} \sim 0.7 \mathrm{~mm} \mathrm{~s}^{-1}$ and a strong tailing up to $\sim 2 \mathrm{~mm} \mathrm{~s}^{-1}$ (Table 2, Figure 2A,C). In Fe(III) minerals, $\Delta \mathrm{E}_{\mathrm{Q}}$ is influenced by interactions of $\mathrm{Fe}$ with other ions in the mineral lattice (Rancourt, 1998). Higher $\Delta \mathrm{E}_{Q}$ correspond to a higher degree of distortion relative to a perfect polyhedral ligand electric field (Rea et al., 1994). Such lattice distortions arise due to the presence of foreign ligands other than $\mathrm{O}$ and OH, e.g. DOM (Eusterhues et al., 2008), Al (Cismasu et al., 2012), Si (Cismasu et al., 2014) and $\mathrm{P}$ (Voegelin et al., 2010). The broad distribution of $\Delta \mathrm{E}_{\mathrm{Q}}$ indicates the coexistence of different $\mathrm{Fe}$ (III) environments in the Fe-OM co-precipitates, each with a characteristic degree of lattice distortion. Beside $\mathrm{Fe}$ oxide composition-induced shifts in $\Delta \mathrm{E}_{\mathrm{Q}}$, positively skewed distributions of $\Delta \mathrm{E}_{\mathrm{Q}}$ were also explained with surface effects, in which surface-near $\mathrm{Fe}$ (III) polyhedra exhibit a more deformed coordination than the inner $\mathrm{Fe}$ (III) polyhedra (De Grave et al., 1986; Rea et al., 1994). A high proportion of surface-near Fe sites would also contribute to the pronounced tailing at higher $\Delta \mathrm{E}_{Q}$ as observed in our study (Figure $2 \mathrm{~A}, \mathrm{C}$ ), provided that the 
crystallite sizes of the Fe-OM co-precipitates are comparably small. Referring to Fe oxide precipitation experiments with DOM (Eusterhues et al., 2008), Si (Cismasu et al., 2014) and As (Erbs et al., 2010; Rancourt et al., 2001), small crystallite sizes can be assumed for the Fe-OM coprecipitates in our study. The absence of distinct reflexes in the X-ray diffractograms indicates the absence of enhanced scattering domains and therefore supports this assumption (Figure EA-14). Contrary to our expectations, $\Delta \mathrm{E}_{\mathrm{Q}}$-distributions were not shifted towards higher values for Ahderived Fe-OM co-precipitates with increasing contents in $\mathrm{OC}, \mathrm{Al}$ and $\mathrm{P}$, i.e. with increasing PVs (Figure 2A,C). Theoretically, the OC/P/Al-induced increase in lattice distortion could have been outbalanced by the coincidently decreasing average Si content in the Fe-OM co-precipitates. We exclude this scenario due to the small decrease in Si/Fe of $\sim 0.03$ (Figure 1D) compared to the coincident increase in $\mathrm{P} / \mathrm{Fe}(\sim 0.1)$ and $\mathrm{OC} / \mathrm{Fe}(\sim 1)$ and the comparably low distortion effect by $\mathrm{Si}$ (Rancourt et al., 2001). Although the distribution of $\Delta \mathrm{E}_{\mathrm{Q}}$ contains the most crystal chemical information, which can be extracted from a Mössbauer spectrum (Rancourt et al., 2001), any changes in the crystallinity of the Fe-OM co-precipitates of our study may not be reflected by according shifts in the $\Delta \mathrm{E}_{\mathrm{Q}}$-distributions. Such difficulties arise in the evaluation of Mössbauer spectra, if low-crystalline phases are compared with even lower crystalline phases (De Grave et al., 1986). This is the particular difference of our study compared to other studies, in which pure Fe oxides were treated with stepwise increased concentrations of additives (e.g. Eusterhues et al. (2008); Mikutta et al. (2008)). In contrast to our study, the expected trend of increasing $\Delta \mathrm{E}_{\mathrm{Q}}$ with increasing lattice distortion could be revealed in the cited studies. An alternative explanation of the constant $\Delta \mathrm{E}_{\mathrm{Q}}$ is that increasing contents in $\mathrm{OC}, \mathrm{Al}$ and $\mathrm{P}$ exclusively sorbed to the surface of crystallites rather than being incorporated into the crystal structure. However, this contradicts with the observed elemental compositions of the Fe-OM co-precipitates, which pointed to the linkage of Fe polyhedra via phosphate, arsenate and $\mathrm{Ca}$ ions (section 4.1.).

In the $5 \mathrm{~K}$-Mössbauer spectra, two components with the same $\Delta \mathrm{E}_{\mathrm{Q}}$ and $\delta$ but variable magnetic hyperfine fields $\left(B_{h f}\right)$ were applied to fit the asymmetric sextets. With one exception (discussed below), the obtained $B_{h f}$ distributions were negatively skewed and covered a wide range of $35-53$ T (Table 2, Figure 2B,D). In their study on magnetically-split ferrihydrite, Murad and Schwertmann (1980) presented negatively skewed $B_{h f}$ distributions covering a broad range from $<40 \mathrm{~T}$ to $55 \mathrm{~T}$, while the lower $B_{h f}$ values were more pronounced in natural samples. $A$ lower $B_{h f}$ at constant $\Delta E_{Q}$ points to a higher perturbation of crystallite interactions (Morup and Ostenfeld, 2001). Murad and Schwertmann (1980) assumed the existence of planar arranged $\mathrm{Fe}(\mathrm{O}, \mathrm{OH})_{6}$ octahedra without any stacking perpendicular to that plane in the samples with low $B_{h f}$. Considering their average $B_{h f} \sim 46$ $\mathrm{T}$ (Table 2), which is below the reported range of $47-50 \mathrm{~T}$ for ferrihydrite (Cornell and Schwertmann, 2003), such elementary arrangements of Fe polyhedra can also be expected in the 
Fe-OM co-precipitates from our study. In contrast to $\Delta \mathrm{E}_{\mathrm{Q}}$, a consistent shift in $\mathrm{B}_{\mathrm{hf}}$-distributions to lower values was observed for the Fe-OM co-precipitates with increasing contents in OM, $\mathrm{P}$ and $\mathrm{Al}$, i.e. with increasing PVs. Such compounds are known to decrease the crystallite interactions due to magnetic dilution (Cornell and Schwertmann, 2003; Mikutta et al., 2008). Increased contents of such "foreign" species in the Fe precipitates will therefore result in an increase of lower $B_{h f}$ at the expense of higher $B_{h f}$ and will consequently induce the observed $B_{h f}$-distribution shift to lower values. The crystallite interactions and thus the long-range order, if any in the Fe-OM-coprecipitates, are therefore decreased with increasing PVs. Because of their different oxidation states, the increased incorporation of foreign species such as $\mathrm{OM}, \mathrm{P}$, and $\mathrm{Al}$ may be more reflected by $\mathrm{B}_{\mathrm{hf}}$-values in the $5 \mathrm{~K}$-spectra compared to $\Delta \mathrm{E}_{\mathrm{Q}}$-values in the $77 \mathrm{~K}$-spectra. While distortion of polyhedral leading to differences in $\Delta \mathrm{E}_{\mathrm{Q}}$ depends on the foreign cations ionic radius, cations with an oxidation state different from Fe(III)-cations result in the decrease of $B_{h f}$ values.

The average values of $\Delta \mathrm{E}_{\mathrm{Q}}$ and $\mathrm{B}_{\mathrm{hf}}$ indicate the predominance of very low-crystalline ferrihydrite in the Fe-OM co-precipitates. The Fe-OM co-precipitates from the Ap-derived effluents are slightly more crystalline than those from the Ah-derived effluents, which comprises less distorted Fe sites (lower $\Delta \mathrm{E}_{\mathrm{Q}}$ ) and more intense crystallite interactions (higher $\mathrm{B}_{\mathrm{hf}}$ ). The significant presence of As exclusively in the Ah-derived Fe-OM co-precipitates (As/Fe $\sim 0.06$, Figure 1B) very likely contributed to these differences. Incorporated As is known to increase structural disorder and thus $\Delta \mathrm{E}_{\mathrm{Q}}$ (Rancourt et al., 2001) and decrease crystallite interactions and thus $\mathrm{B}_{\mathrm{hf}}$ (Erbs et al., 2010). The very low $B_{h f}$, which are represented by a dedicated component with $B_{h f}<44 T$, might indicate the presence of lepidocrocite as previously detected in $\mathrm{Fe}$ - and As-rich organic flocs from streambeds (ThomasArrigo et al., 2014). If magnetically ordered, lepidocrocite exhibits $\mathrm{B}_{\mathrm{hf}}<46 \mathrm{~T}$, which is lower than ferrihydrite (Murad and Schwertmann, 1984). However, in a paramagnetic state, the lepidocrocite $\Delta E_{Q}$ value is significantly lower than that of ferrihydrite $\left(0.53 \mathrm{~mm} \mathrm{~s}^{-1}\right.$ compared to $0.62-0.78 \mathrm{~mm} \mathrm{~s}^{-1}$, respectively; Murad and Cashion (2004)). The presence of lepidocrocite is therefore not consistent with our $77 \mathrm{~K}$-results. Assuming that Mössbauer recoilless fractions of all Fe-bearing components are equal, such that subspectral areas match to the $\mathrm{Fe}$ amount in the corresponding phase, lepidocrocite should be present in significant amounts (30 $40 \%$ of $\mathrm{Fe}_{\text {Total }}$; Table 2: $\mathrm{P}(\%)$ of component 2 in the fits of the $5 \mathrm{~K}$-spectra). This assumption is valid at cryogenic temperatures (Rancourt, 1998). Even if lepidocrocite would be low-crystalline and Xray amorphous (ThomasArrigo et al., 2014), the lepidocrocite-typical short-range order is detectable in vibrational spectra, i.e. in FTIR spectra. Consequently, distinct bands and/or shoulders from lepidocrocite are mandatory in the FTIR spectra of the Fe-OM co-precipitates if lepidocrocite would represent this important constituent in the Fe-OM co-precipitates as indicated by Mössbauer spectroscopy. This is still valid under consideration of band shifting and broadening, 
which was observed in the FTIR spectra of low-crystalline lepidocrocite (Schwertmann and Wolska, 1990). However, we could not detect bands in the FTIR spectra characteristic of lepidocrocite (Figure 3). We therefore exclude its presence in the Fe-OM co-precipitates from soil effluents. Voegelin et al. (2010) and Schwertmann et al. (2005) observed no precipitation of lepidocrocite as long as silicate and OM from a humus layer, respectively, were available to precipitate with $\mathrm{Fe}$. As indicated by higher ratios of $\mathrm{OC} / \mathrm{Fe}$ and $\mathrm{Si} / \mathrm{Fe}$ in the effluent compared to their relative contents in the Fe-OM co-precipitates (Figure 1A,D), both compounds were not depleted from solution during the formation of the Fe-OM co-precipitates. This excess in aqueous silicate and $\mathrm{OM}$ renders the precipitation of lepidocrocite unlikely.

A significant presence of $\mathrm{Fe}(\mathrm{III})$ phosphate and $\mathrm{Fe}(\mathrm{III})$ arsenate as demonstrated in Mikutta et al. (2014a) can also be excluded, because both phases are lacking magnetic ordering at $5 \mathrm{~K}$. We observed neither doublets nor collapsed sextets in the $5 \mathrm{~K}$-Mössbauer spectra of the soil effluentderived Fe-OM co-precipitates. The absence of $\mathrm{Fe}$ (III)phosphates was not expected with respect to the shifts in the mean elemental composition of the Fe-OM co-precipitates. Assuming a stoichiometric ratio of $\mathrm{P} / \mathrm{Fe}=0.5$ in $\mathrm{Fe}$ (III)phosphates (Gunnars et al., 2002; Lienemann et al., 1999; Thibault et al., 2009), $3-18 \%$ of $\mathrm{Fe}_{\text {Total }}$ would be present as $\mathrm{Fe}$ (III)phosphate, which is above the detection limit of $\sim 2 \% \mathrm{Fe}_{\text {Total }}$ in Mössbauer spectroscopy. A possible explanation is that structural modifications of the $\mathrm{Fe}$ (III)phosphates from $\mathrm{pH}$-neutral solutions (this study) compared to such from strongly acidic solutions ( $\mathrm{pH}<2$; Mikutta et al. (2014a)) could have increased their Néel temperature, which would allow magnetic ordering of the former at $5 \mathrm{~K}$. However, the magnetic properties of $\mathrm{Fe}(\mathrm{III})$ phosphates/arsenates in dependence on the formation conditions must be investigated in dedicated experiments to allow robust statements.

Considering the distributions of $\Delta \mathrm{E}_{\mathrm{Q}}$ and $\mathrm{B}_{\mathrm{hf}}$, the Fe-OM co-precipitates from one of the Ap-soil columns (Ap_1) were clearly different from the remaining Fe-OM co-precipitates (Figure2). The contribution of higher $B_{h f}$ could be explained with the presence of small amounts of nanogoethite. This Fe oxide phase was detected in marine sediments (van der Zee et al., 2003) and in soils (Thompson et al., 2011). Bht-values of nanogoethite peak at $~ 50 \mathrm{~T}$ (Thompson et al., 2011). Since Guyodo et al. (2003) revealed superparamagnetic nanogoethite at temperatures $>35 \mathrm{~K}$, the absence of sextets in the $77 \mathrm{~K}$-spectrum of Ap_1 would not be contradictory to the presence of such low-crystalline goethite. However, the shift in $\Delta \mathrm{E}_{\mathrm{Q}}$-distribution to values $<0 \mathrm{~mm} \mathrm{~s}^{-1}$ is contrary to the presence of nanogoethite. Doublets of superparamagnetic goethite were described with $\Delta \mathrm{E}_{Q}$ $\sim 1 \mathrm{~mm} \mathrm{~s}^{-1}$ (Bocquet et al., 1992), which even exceeds $\Delta \mathrm{E}_{Q}$ for doublets of low-crystalline ferrihydrite $\left(\sim 0.8 \mathrm{~mm} \mathrm{~s}^{-1}\right)$. Consequently, the presence of nanogoethite in the Fe-OM coprecipitates should result in a $\Delta \mathrm{E}_{\mathrm{Q}}$-distribution shift to higher values, which is opposed to the observation. In addition, goethite can be distinguished by its low $\varepsilon$ (quadrupole shift) value of 
$-0.125 \mathrm{~mm} \mathrm{~s}^{-1}$ in magnetically ordered spectra (Cornell and Schwertmann, 2003) compared to $\varepsilon \sim$ $-0.010 \mathrm{~mm} \mathrm{~s}^{-1}$ measured for the Fe-OM co-precipitates from Ap_1. Consequently, we cannot attribute the shifts in $\Delta \mathrm{E}_{\mathrm{Q}^{-}}$and $\mathrm{B}_{\mathrm{hf}}$-distributions of $\mathrm{Ap} \_1$ to the presence of minor amounts of nanogoethite. We also cannot provide a further explanation for this observation on basis of the present data other than that this may be an artefact of the poor signal-to-noise ratio in the spectra from this particular sample. Additionally, these distribution shifts were not reproduced in the effluent from the replicate soil column (Figure 2). The absence of nanogoethite in all Fe-OM coprecipitates may be related to the constant availability of significant amounts of $\mathrm{OM}, \mathrm{P}, \mathrm{Al}, \mathrm{Si}$ and As (only in Ah-derived effluent). Soil OM (Schwertmann, 1966), P (Châtellier et al., 2013), Al (Masue-Slowey et al., 2011), silicate (Cismasu et al., 2014) and As (Ford, 2002) are known to stabilize Fe polyhedra in very primitive arrangements, i.e. low-crystalline ferrihydrite.

\subsection{Colloidal properties of the Fe-OM co-precipitates}

The degree of aggregation of the Fe-OM co-precipitates decreased with increasing PVs resulting in smaller aggregate sizes with ascendant effluent fraction numbers. Despite the formation of $>100$ $\mathrm{nm}$ aggregates, very small-sized aggregates $(<20 \mathrm{~nm})$ were permanently present in all effluent fractions independent of the aggregation intensity. This points to an aggregation that could not affect all particles homogeneously but rather ceased at a certain point of time when both large and small aggregates had formed. As a consequence, a continuum of Fe-OM co-precipitate aggregate sizes must be expected after oxidation of $\mathrm{Fe}^{2+}$ in soil-derived solutions. Solely electrostatic repulsion was insufficient to prevent aggregation considering $\left|U_{E}\right|<30 \mathrm{mV}$ for all colloidal Fe-OM co-precipitates (Table 1, Stumm and Morgan (1996)). The Fe-OM co-precipitates were rather stabilized against further aggregation (time-frame: months) due to steric repulsion between the moieties of the aggregate-associated OM. The measured $U_{E}$ agreed with natural OM-stabilized nanomaterials from natural aqueous systems (Loux and Savage, 2008).

\subsection{Applicability of soil column outflow experiments}

Although the investigated topsoils differed in their texture, composition and utilization, they showed a similar response to shifts in the redox regime from oxic to anoxic conditions. In both topsoils, limited supply of $\mathrm{O}_{2}$ due to microbial activity under water-saturated conditions resulted in microbial $\mathrm{Fe}(\mathrm{III})$ reduction. Despite the different effluent composition, similarly composed Fe-OM coprecipitates formed in all fractions after oxidation of effluent $\mathrm{Fe}^{2+}$. This experimental setup represents an approach to utilize self-contained soil systems on laboratory scale to produce soilrelevant Fe-OM co-precipitates. 


\section{ENVIRONMENTAL IMPLICATIONS}

As expected, the elemental composition of the Fe-OM co-precipitates is highly dependent on the composition of the solution, from which they precipitate. In light of the transient composition of soil solutions, highly variable elemental compositions of Fe-OM co-precipitates can be expected in redoximorphic soils and other transient systems with redox changes and boundaries. The shifts in average elemental compositions of the Fe precipitates can be explained with the sequential precipitation of $\mathrm{Fe}$ (III)phosphates/arsenates before low-crystalline $\mathrm{Fe}$ oxides will form. This was proposed for inorganic systems (Voegelin et al., 2010) but applies surprisingly well also to soilderived solutions, which contain a multitude of organic compounds, which likely affect the $\mathrm{Fe}$ (III) nucleation and polymerization of Fe polyhedra. Following the idea of sequential precipitation of $\mathrm{Fe}$ (III)phases, the competition for association with Fe polyhedra, e.g. between phosphate and silicate, is therefore predictable in transiently composed solutions even in presence of organic compounds.

Independent from solution composition, a broad size distribution of the $\mathrm{Fe}-\mathrm{OM}$ co-precipitate aggregates must be expected after their aggregation has finished. This broad distribution involves colloidal and non-colloidal fractions, which will consequently result in highly diverse mobility and availability of the Fe-OM co-precipitates. Unaffected by their elemental composition, the Fe-OM coprecipitates could be best described as very low-crystalline ferrihydrite, while a considerable fraction exhibited even lower crystallinity than characteristic of ferrihydrite. Such Fe-OM coprecipitates can be regarded as initial $\mathrm{Fe}$-bearing phase after $\mathrm{Fe}^{2+}$-oxidation in soil-derived solutions. They differ from lake and marine sediments (van der Zee et al., 2003), mine tailings (Filip et al., 2007) and soils (Thompson et al., 2011), in which nanogoethite contributed to the mineral composition. However, we would not expect dramatic differences in the properties of these low-crystalline phases and their function in the environment. This expectation is based on Murad and Schwertmann (1980), who stated that individual characteristics of the different Fe oxides gradually disappear as particle sizes decrease and finally only fundamental structural elements of short-range order common to all $\mathrm{Fe}$ oxides remain, i.e. the $\mathrm{Fe}(\mathrm{O}, \mathrm{OH})_{6}$ octahedra. For related studies on the properties of $\mathrm{Fe}$ phases, which are characteristic of soils and sediments, we recommend the soil column outflow experiments to produce such Fe phases on laboratory scale. Owing to the significant presence of proteins and polysaccharides in the soil effluent-derived FeOM co-precipitates, we expect significant differences in their biogeochemical behavior compared to synthetic counterparts, which are synthesized with organic proxies, e.g. humic substances. This was recently confirmed concerning their ecotoxicity (Höss et al., 2015). 


\section{ACKNOWLEDGEMENTS}

This study was funded by the German Federal Ministry of Education and Research (Nanosan (03X0085D) and INFLUINS (03IS20921A)). C. Schröder acknowledges a postdoctoral appointment at the Universities of Bayreuth and Tübingen funded by the Deutsche Forschungsgemeinschaft (research unit FOR 580). We thank J. Braunschweig and F. Wagner for putting their efforts in the pre-experiments and $\mathrm{K}$. Eusterhues, A. Thompson and the anonymous reviewers for their helpful comments on the manuscript.

\section{APPENDIX A. SUPPLEMENTARY DATA}

Supplementary data associated with this article can be found in the online version. 


\section{REFERENCES}

Arai Y. and Sparks D.L. (2001) ATR-FTIR spectroscopic investigation on phosphate adsorption mechanisms at the ferrihydrite-water interface. J. Colloid Interface Sci. 241, 317-326.

Baken S., Nawara S., Van Moorleghem C. and Smolders E. (2014) Iron colloids reduce the bioavailability of phosphorus to the green alga Raphidocelis subcapitata. 59, 198-206.

Banfield J.F. and Zhang H.Z. (2001) Nanoparticles in the environment. In Nanoparticles and the Environment. Mineralogical Soc. America, Washington, pp. 1-58.

Bocquet S., Pollard R.J. and Cashion J.D. (1992) Dynamic magnetic phenomena in fine-particle goethite. Phys. Rev. $B$ 46, 11657-11664.

Brandt O. (2003) Eintrags- und Wirkungspfade von Schwermetallen und Arsen in Flußaue-Systemen am Beispiel der Mulde zwischen Bitterfeld/Wolfen und Dessau, Sachsen-Anhalt. PhD Thesis. Bauingenieurwesen und Angewandte Geowissenschaften, Technische Universität Berlin.

Carlson L. and Schwertmann U. (1981) Natural ferrihydrites in surface deposits from Finland and their association with silica. Geochim. Cosmochim. Acta 45, 421-429.

Châtellier X., Grybos M., Abdelmoula M., Kemner K.M., Leppard G.G., Mustin C., West M.M. and Paktunc D. (2013) Immobilization of $\mathrm{P}$ by oxidation of $\mathrm{Fe}(\mathrm{II})$ ions leading to nanoparticle formation and aggregation. Appl. Geochem. 35, 325-339.

Cismasu A.C., Michel F.M., Stebbins J.F., Levard C. and Brown G.E. (2012) Properties of impurity-bearing ferrihydrite I. Effects of Al content and precipitation rate on the structure of 2-line ferrihydrite. Geochim. Cosmochim. Acta 92, 275-291.

Cismasu A.C., Michel F.M., Tcaciuc A.P. and Brown G.E. (2014) Properties of impurity-bearing ferrihydrite III. Effects of $\mathrm{Si}$ on the structure of 2-line ferrihydrite. Geochim. Cosmochim. Acta 133, 168-185.

Cornell R.M. and Schwertmann U. (2003) The Iron Oxides. 2nd ed. Wiley-VCH, Weinheim.

Davis W.M., Erickson C.L., Johnston C.T., Delfino J.J. and Porter J.E. (1999) Quantitative Fourier Transform Infrared spectroscopic investigation of humic substance functional group composition. Chemosphere 38, 2913-2928.

De Grave E., Persoons R.M., Chambaere D.G., Vandenberghe R.E. and Bowen L.H. (1986) An Fe-57 Mössbauer-effect study of poorly crystalline gamma-FeOOH. Phys. Chem. Miner. 13, 61-67.

Doelsch E., Stone W.E.E., Petit S., Masion A., Rose J., Bottero J.Y. and Nahon D. (2001) Speciation and crystal chemistry of $\mathrm{Fe}(\mathrm{III})$ chloride hydrolyzed in the presence of $\mathrm{SiO}_{4}$ ligands. 2. Characterization of $\mathrm{Si}-\mathrm{Fe}$ aggregates by FTIR and ${ }^{29} \mathrm{Si}$ solid-state NMR. Langmuir 17, 1399-1405.

Dryer D.J., Korshin G.V. and Fabbricino M. (2008) In situ examination of the protonation behavior of fulvic acids using differential absorbance spectroscopy. Environ. Sci. Technol. 42, 6644-6649.

Erbs J.J., Berquó T.S., Reinsch B.C., Lowry G.V., Banerjee S.K. and Penn R.L. (2010) Reductive dissolution of arsenicbearing ferrihydrite. Geochim. Cosmochim. Acta 74, 3382-3395.

Eusterhues K., Rennert T., Knicker H., Kögel-Knabner I., Totsche K.U. and Schwertmann U. (2011) Fractionation of organic matter due to reaction with ferrihydrite: Coprecipitation versus adsorption. Environ. Sci. Technol. 45, 527533.

Eusterhues K., Wagner F.E., Hausler W., Hanzlik M., Knicker H., Totsche K.U., Kogel-Knabner I. and Schwertmann U. (2008) Characterization of ferrihydrite-soil organic matter coprecipitates by X-ray diffraction and Mössbauer spectroscopy. Environ. Sci. Technol. 42, 7891-7897.

Filip J., Zboril R., Schneeweiss O., Zeman J., Cernik M., Kvapil P. and Otyepka M. (2007) Environmental applications of chemically pure natural ferrihydrite. Environ. Sci. Technol. 41, 4367-4374.

Ford R.G. (2002) Rates of hydrous ferric oxide crystallization and the influence on coprecipitated arsenate. Environ. Sci. Technol. 36, 2459-2463.

Frierdich A.J., Luo Y. and Catalano J.G. (2011) Trace element cycling through iron oxide minerals during redox-driven dynamic recrystallization. Geology 39, 1083-1086.

Fritzsche A., Dienemann H. and Dudel E.G. (2006) Arsenic fixation on iron-hydroxide-rich and plant litter-containing sediments in natural environments. Environ. Geol. 51, 133-142.

Fritzsche A., Rennert T. and Totsche K.U. (2011) Arsenic strongly associates with ferrihydrite colloids formed in a soil effluent. Environ. Pollut. 159, 1398-1405.

Gilbert B. and Banfield J.F. (2005) Molecular-scale processes involving nanoparticulate minerals in biogeochemical systems. Rev. Mineral Geochem. 59, 109-155.

Gunnars A., Blomqvist S., Johansson P. and Andersson C. (2002) Formation of Fe(III) oxyhydroxide colloids in freshwater and brackish seawater, with incorporation of phosphate and calcium. Geochim. Cosmochim. Acta 66, 745-758. 
Gütlich G. and Schröder C. (2012) Mössbauer Spectroscopy. In Methods in Physical Chemistry (eds. R. Schäfer and P.C. Schmidt). Wiley-VCH, Weinheim, pp. 351-389.

Guyodo Y., Mostrom A., Lee Penn R. and Banerjee S.K. (2003) From nanodots to nanorods: Oriented aggregation and magnetic evolution of nanocrystalline goethite. Geophys. Res. Lett. 30, 1512.

Höss S., Fritzsche A., Meyer C., Bosch J., Meckenstock R.U. and Totsche K.U. (2015) Size- and composition-dependent toxicity of synthetic and soil-derived Fe oxide colloids for the nematode Caenorhabditis elegans. Environ. Sci. Technol. 49, 544-552.

IUSS Working Group. (2006) World reference base for soil resources. A framework for international classification, correlation and communication., Rome.

Kashyap S., Woehl T.J., Liu X., Mallapragada S.K. and Prozorov T. (2014) Nucleation of iron oxide nanoparticles mediated by Mms6 protein in situ. ACS Nano 8, 9097-9106.

Kim H. and Park H. (2008) Nonnegative matrix factorization based on alternating nonnegativity constrained least squares and active set method. SIAM J. Matrix Anal. A. 30, 713-730.

Kleber M. and Johnson M.G. (2010) Advances in understanding the molecular structure of soil organic matter: Implications for interactions in the environment. In Advances in Agronomy 106 (ed. D.L. Sparks). Academic Press, San Diego, pp. 77-142.

Li Y.C., Yu S., Strong J. and Wang H.L. (2012) Are the biogeochemical cycles of carbon, nitrogen, sulfur, and phosphorus driven by the "Fe-III-Fe-II redox wheel" in dynamic redox environments? J. Soils Sediments 12, 683693.

Lienemann C.P., Monnerat M., Dominik J. and Perret D. (1999) Identification of stoichiometric iron-phosphorus colloids produced in a eutrophic lake. Aquat. Sci. 61, 133-149.

Liu X., Eusterhues K., Thieme J., Ciobota V., Höschen C., Mueller C.W., Küsel K., Kögel-Knabner I., Rösch P., Popp J. and Totsche K.U. (2013) STXM and NanoSIMS investigations on EPS fractions before and after adsorption to goethite. Environ. Sci. Technol. 47, 3158-3166.

Loux N.T. and Savage N. (2008) An assessment of the fate of metal oxide nanomaterials in porous media. Water Air Soil Pollut. 194, 227-241.

Lovley D.R. and Phillips E.J.P. (1988) Novel mode of microbial energy-metabolism - Organic carbon oxidation coupled to dissimilatory reduction of iron or manganese. Appl. Environ. Microbiol. 54, 1472-1480.

Masue-Slowey Y., Loeppert R.H. and Fendorf S. (2011) Alteration of ferrihydrite reductive dissolution and transformation by adsorbed As and structural Al: Implications for As retention. Geochim. Cosmochim. Acta 75, 870-886.

Mikutta C., Mikutta R., Bonneville S., Wagner F., Voegelin A., Christl I. and Kretzschmar R. (2008) Synthetic coprecipitates of exopolysaccharides and ferrihydrite. Part I: Characterization. Geochim. Cosmochim. Acta 72 , 1111-1127.

Mikutta C., Schröder C. and Marc Michel F. (2014a) Total X-ray scattering, EXAFS, and Mössbauer spectroscopy analyses of amorphous ferric arsenate and amorphous ferric phosphate. Geochim. Cosmochim. Acta 140, 708-719.

Mikutta R., Lorenz D., Guggenberger G., Haumaier L. and Freund A. (2014b) Properties and reactivity of Fe-organic matter associations formed by coprecipitation versus adsorption: Clues from arsenate batch adsorption. Geochim. Cosmochim. Acta 144, 258-276.

Mikutta R., Schaumann G.E., Gildemeister D., Bonneville S., Kramer M.G., Chorover J., Chadwick O.A. and Guggenberger G. (2009) Biogeochemistry of mineral-organic associations across a long-term mineralogical soil gradient (0.3-4100 kyr), Hawaiian Islands. Geochim. Cosmochim. Acta 73, 2034-2060.

Morup S. and Ostenfeld C.W. (2001) On the use of Mössbauer spectroscopy for characterisation of iron oxides and oxyhydroxides in soils. Hyperfine Interact. 136, 125-131.

Murad E. and Cashion J.D. (2004) Mössbauer Spectroscopy of Environmental Materials and their Industrial Utilization. Springer, New York.

Murad E. and Schwertmann U. (1980) The Mössbauer spectrum of ferrihydrite and its relations to thise of other iron oxides. Am. Mineral. 65, 1044-1049.

Murad E. and Schwertmann U. (1984) The influence of crystallinity on the Mössbauer spectrum of lepidocrocite. 48, 507-511.

Murray J.W., Codispoti L.A. and Friederich G.E. (1995) Oxidation-reduction environments. In Aquatic Chemistry Interfacial and Interspecies Processes (eds. C.P. Huang, C.R. O’Melia and J.J. Morgan). American Chemical Society, Washington, D.C., pp. 157-176.

Omoike A., Chorover J., Kwon K.D. and Kubicki J.D. (2004) Adhesion of bacterial exopolymers to alpha-FeOOH: Innersphere complexation of phosphodiester groups. Langmuir 20, 11108-11114.

Peak D., Ford R.G. and Sparks D.L. (1999) An in situ ATR-FTIR investigation of sulfate bonding mechanisms on goethite. J. Colloid. Interf. Sci. 218, 289-299. 
Prietzel J., Wu Y., Dumig A., Zhou J. and Klysubun W. (2013) Soil sulphur speciation in two glacier forefield soil chronosequences assessed by S K-edge XANES spectroscopy. Eur. J. Soil Sci. 64, 260-272.

Rancourt D.G. (1998) Mössbauer spectroscopy in clay science. Hyperfine Interact. 117, 3-38.

Rancourt D.G., Fortin D., Pichler T., Thibault P.J., Lamarche G., Morris R.V. and Mercier P.H.J. (2001) Mineralogy of a natural As-rich hydrous ferric oxide coprecipitate formed by mixing of hydrothermal fluid and seawater: Implications regarding surface complexation and color banding in ferrihydrite deposits. Am. Miner. 86, 834-851.

Rancourt D.G. and Ping J.Y. (1991) Voigt-based methods for arbitrary-shape static hyperfine parameter distributions in Mössbauer spectroscopy. Nucl. Instrum. Meth. B 58, 85-97.

Rea B.A., Davis J.A. and Waychunas G.A. (1994) Studies of the reactivity of the ferrihydrite surface by iron isotopic exchange and Mössbauer spectroscopy. Clay Clay Miner. 42, 23-34.

Schuth S., Hurrass J., Muenker C. and Mansfeldt T. (2015) Redox-dependent fractionation of iron isotopes in suspensions of a groundwater-influenced soil. Chem. Geol. 392, 74-86.

Schwertmann U. (1966) Inhibitory effect of soil organic matter on crystallization of amorphous ferric hydroxide. Nature 212, 645-646.

Schwertmann U. and Cornell R.M. (2000) Iron oxides in the labaratory. 2nd ed. WILEY-VCH Verlag GmbH, Weinheim.

Schwertmann U., Wagner F. and Knicker H. (2005) Ferrihydrite-humic associations: Magnetic hyperfine interactions. Soil Sci. Soc. Am. J. 69, 1009-1015.

Schwertmann U. and Wolska E. (1990) The influence of aluminum on iron oxides. 15. Al-for-Fe substitution in synthetic lepidocrocite. Clay Clay Mineral. 38, 209-212.

Socrates G. (2001) Infrared and Raman characteristic group frequencies: Tables and charts. 3rd ed. John Wiley \& Sons Ltd, Chichester.

Stumm W. and Morgan J.J. (1996) Particle-particle interaction: Colloids, coagulation, and filtration. In Aquatic Chemistry - Chemical Equilibria and Rates in Natural Waters. John Wiley and Sons, New York, pp. 819-871.

Swedlund P.J., Miskelly G.M. and McQuillan A.J. (2009) An attenuated total reflectance IR study of silicic acid adsorbed onto a ferric oxyhydroxide surface. Geochim. Cosmochim. Acta 73, 4199-4214.

Thibault P.-J., Rancourt D.G., Evans R.J. and Dutrizac J.E. (2009) Mineralogical confirmation of a near-P:Fe=1:2 limiting stoichiometric ratio in colloidal P-bearing ferrihydrite-like hydrous ferric oxide. Geochim. Cosmochim. Acta 73, 364376.

ThomasArrigo L.K., Mikutta C., Byrne J., Barmettler K., Kappler A. and Kretzschmar R. (2014) Iron and arsenic speciation and distribution in organic flocs from streambeds of an arsenic-enriched peatland. Environ. Sci. Technol. 48, 13218-13228.

Thompson A., Chadwick O.A., Rancourt D.G. and Chorover J. (2006) Iron-oxide crystallinity increases during soil redox oscillations. Geochim. Cosmochim. Acta 70, 1710-1727.

Thompson A., Rancourt D.G., Chadwick O.A. and Chorover J. (2011) Iron solid-phase differentiation along a redox gradient in basaltic soils. Geochim. Cosmochim. Acta 75, 119-133.

van der Zee C., Roberts D.R., Rancourt D.G. and Slomp C.P. (2003) Nanogoethite is the dominant reactive oxyhydroxide phase in lake and marine sediments. Geology 31, 993-996.

van Genuchten C.M., Gadgil A.J. and Pena J. (2014) Fe(III) nucleation in the presence of bivalent cations and oxyanions leads to subnanoscale 7 angstrom polymers. Environ. Sci. Technol. 48, 11828-11836.

Voegelin A. and Hug S.J. (2003) Catalyzed oxidation of arsenic(III) by hydrogen peroxide on the surface of ferrihydrite: An in situ ATR-FTIR study. Environ. Sci. Technol. 37, 972-978.

Voegelin A., Kaegi R., Frommer J., Vantelon D. and Hug S.J. (2010) Effect of phosphate, silicate, and Ca on Fe(III)precipitates formed in aerated $\mathrm{Fe}(\mathrm{II})$ - and $\mathrm{As}(\mathrm{III})$-containing water studied by X-ray absorption spectroscopy. Geochim. Cosmochim. Acta 74, 164-186.

Wang X., Li W., Harrington R., Liu F., Parise J.B., Feng X. and Sparks D.L. (2013) Effect of ferrihydrite crystallite size on phosphate adsorption reactivity. Environ. Sci. Technol. 47, 10322-10331.

Waychunas G.A., Kim C.S. and Banfield J.F. (2005) Nanoparticulate iron oxide minerals in soils and sediments: unique properties and contaminant scavenging mechanisms. J. Nanopart. Res. 7, 409-433.

Weber K.A., Achenbach L.A. and Coates J.D. (2006) Microorganisms pumping iron: anaerobic microbial iron oxidation and reduction. Nat. Rev. Microbiol. 4, 752-764.

Wehrer M. and Totsche K.U. (2003) Detection of non-equilibrium contaminant release in soil columns: Delineation of experimental conditions by numerical simulations. J. Plant Nutr. Soil Sci. 166, 475-483.

Weigand H. and Totsche K.U. (1998) Flow and reactivity effects on dissolved organic matter transport in soil columns. Soil Sci. Soc. Am. J. 62, 1268-1274. 
Table 1. Electric conductivity (EC), $\mathrm{pH}$ and $\mathrm{Fe}$ size distribution in the soil effluent fractions and properties of the effluent colloids. repl: replicate soil column. BD: before dialysis. AD: after dialysis. $<0.45$ : $0.45 \mu \mathrm{m}$-filtered effluent. $\mathrm{d}_{H}$ : hydrodynamic diameter. $U_{E}$ : Zeta potential. Ah: material from a humus-rich topsoil of the floodplain site. Ap: material from a ploughed topsoil of the agriculture site (Table EA-1). Exchanged pore volumes quantify the effluent volume in relation to the water-accessible pore space volume within the soil column (Ah: $686 \mathrm{~cm}^{3}$ (repl: $664 \mathrm{~cm}^{3}$ ), Ap: $506 \mathrm{~cm}^{3}$ (repl: $\left.510 \mathrm{~cm}^{3}\right)$ ).

\begin{tabular}{|c|c|c|c|c|c|c|c|c|c|c|}
\hline \multirow[t]{2}{*}{ soil } & \multirow{2}{*}{$\begin{array}{l}\text { effluent } \\
\text { fraction }\end{array}$} & & \multirow{2}{*}{$\begin{array}{l}\text { exchanged } \\
\text { pore volume }\end{array}$} & \multicolumn{2}{|c|}{$\mathrm{pH}$} & \multicolumn{2}{|c|}{$\begin{array}{c}\mathrm{EC} \\
\left(\mu \mathrm{S} \mathrm{cm}^{-1}\right)\end{array}$} & \multirow{2}{*}{$\begin{array}{l}\mathrm{Fe}_{<0.45} \pm \sigma \\
\left(\% \mathrm{Fe}_{\text {Total }}\right)^{\#}\end{array}$} & \multirow[t]{2}{*}{$\begin{array}{c}\mathrm{d}_{\mathrm{H}} \pm \sigma \\
(\mathrm{nm})\end{array}$} & \multirow[t]{2}{*}{$\begin{array}{c}U_{E} \pm \sigma \\
(m V)\end{array}$} \\
\hline & & & & $\mathrm{BD}$ & $A D$ & $\mathrm{BD}$ & $A D$ & & & \\
\hline \multirow{8}{*}{ Ah } & \multirow{2}{*}{ Ah_1 } & & $0.00-0.59$ & 7.9 & 5.7 & 442 & 5 & $10.1 \pm 0.3$ & $209 \pm 80$ & $-20 \pm 5$ \\
\hline & & repl & $0.00-0.62$ & 7.9 & 5.8 & 429 & 7 & $7.8 \pm 0.1$ & $206 \pm 83^{\mathrm{a}}$ & $-21 \pm 5$ \\
\hline & \multirow{2}{*}{ Ah_2 } & & $0.60-1.17$ & 7.8 & 5.7 & 342 & 7 & $28.4 \pm 0.5$ & $136 \pm 60$ & $-23 \pm 7$ \\
\hline & & repl & $0.63-1.23$ & 7.7 & 5.7 & 282 & 5 & $36.0 \pm 0.1$ & $119 \pm 51$ & $-17 \pm 8$ \\
\hline & \multirow{2}{*}{ Ah_3 } & & $1.18-1.72$ & 7.5 & 5.6 & 252 & 7 & $34.8 \pm 0.4$ & $62 \pm 18^{b}$ & $-16 \pm 9$ \\
\hline & & repl & $1.24-1.82$ & 7.5 & 5.5 & 225 & 5 & $51.0 \pm 0.2$ & $62 \pm 23^{c}$ & $-17 \pm 10$ \\
\hline & \multirow{2}{*}{ Ah_4 } & & $1.73-2.27$ & 7.3 & 5.5 & 209 & 6 & $45.7 \pm 0.2$ & $43+11^{d}$ & $-17 \pm 9$ \\
\hline & & repl & $1.83-2.40$ & 7.3 & 5.5 & 202 & 5 & $31.9 \pm 0.4$ & $54+18^{e}$ & $-18 \pm 10$ \\
\hline \multirow{6}{*}{ Ap } & \multirow{2}{*}{ Ap_1 } & & $0.09-1.15$ & 8.1 & 6.3 & 1145 & 10 & $0.6 \pm 0.3$ & $-f, g$ & $-g$ \\
\hline & & repl & $0.09-1.07$ & 8.1 & 7.1 & 1033 & 23 & $0.2 \pm 0.2$ & $-f, g$ & $-g$ \\
\hline & \multirow{2}{*}{ Ap_2 } & & $1.24-1.77$ & 8.2 & 5.9 & 703 & 7 & $22.1 \pm 0.1$ & $368 \pm 222^{f}$ & $-15 \pm 5$ \\
\hline & & repl & $1.25-1.78$ & 8.3 & 6.2 & 671 & 6 & $23.1 \pm 0.6$ & $281 \pm 143^{f}$ & $-15 \pm 4$ \\
\hline & \multirow{2}{*}{ Ap_3 } & & * & 7.9 & 5.8 & 516 & 5 & $19.8 \pm 0.3$ & $217 \pm 90^{f}$ & $-17 \pm 4$ \\
\hline & & repl & * & 7.9 & 5.8 & 495 & 5 & $23.9 \pm 0.1$ & $204 \pm 77^{f}$ & $-17 \pm 4$ \\
\hline
\end{tabular}

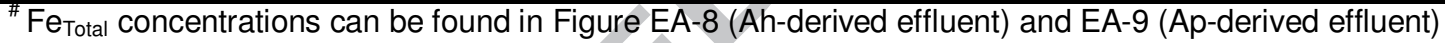

* from subsequent percolations (same conditions; see Figure EA-4 for detailed explanation)

${ }^{a}$ presence of a $2^{\text {nd }}$ size fraction $\left(d_{H}=689 \pm 251 \mathrm{~nm}\right.$; percentage on total scattering intensity: $\left.31 \%\right)$

${ }^{b}$ presence of a $2^{\text {nd }}$ size fraction $\left(d_{H}=512 \pm 151 \mathrm{~nm}\right.$; percentage on total scattering intensity: $\left.16 \%\right)$

${ }^{c}$ presence of a $2^{\text {nd }}$ size fraction ( $d_{H}=712 \pm 239 \mathrm{~nm}$; percentage on total scattering intensity: $20 \%$ )

${ }^{d}$ presence of a $2^{\text {nd }}$ size fraction $\left(d_{H}=510 \pm 102 \mathrm{~nm}\right.$; percentage on total scattering intensity: $52 \%$ )

e presence of a 2 nd size fraction $\left(d_{H}=974 \pm 404 \mathrm{~nm}\right.$; percentage on total scattering intensity: $44 \%$ )

${ }^{f}$ data from $0.45 \mu \mathrm{m}$-filtered effluent (unreliable data in unfiltered effluent due to interferences by non-colloids)

${ }^{g}$ insufficient scattering intensity
} 
Table 2. Center shifts $(\delta$; relative to $\alpha-F e)$, quadrupole splittings $\left(\Delta \mathrm{E}_{Q}\right)$, quadrupole shifts $(\varepsilon)$, magnetic hyperfine fields $\left(\mathrm{B}_{\mathrm{hf}}\right)$ and distribution skew as obtained from fitted ${ }^{57} \mathrm{Fe}-\mathrm{Mössbauer}$ spectra of Fe-OM co-precipitates from the assigned soil effluent fractions (details in Table 1). Two Gaussian components (comp. 1 and 2) were used to achieve sufficiently good fits. Both comp. shared the same $\delta(77 \mathrm{~K})$ and $\delta+\varepsilon(5 \mathrm{~K})$ while the center positions of $\Delta \mathrm{E}_{\mathrm{Q}}(77 \mathrm{~K})$ and $\mathrm{B}_{\mathrm{hf}}(5 \mathrm{~K})$, the corresponding standard deviations $(\sigma)$ and weight factors $(P(\%))$ were fitted to the observed data. mean: composite of both comp. with average magnitude \pm standard deviation of the $\Delta \mathrm{E}_{\mathrm{Q}^{-}}$and $\mathrm{B}_{\mathrm{hf}}$-distributions (Figure 2). $\mathrm{X}^{2}$ red: $\mathrm{X}^{2} /$ number of degrees of freedom. repl: replicate soil column. Mössbauer spectra and fits are presented in Figure EA-13. All fitting and calculated parameters are as defined in Rancourt and Ping (1991).

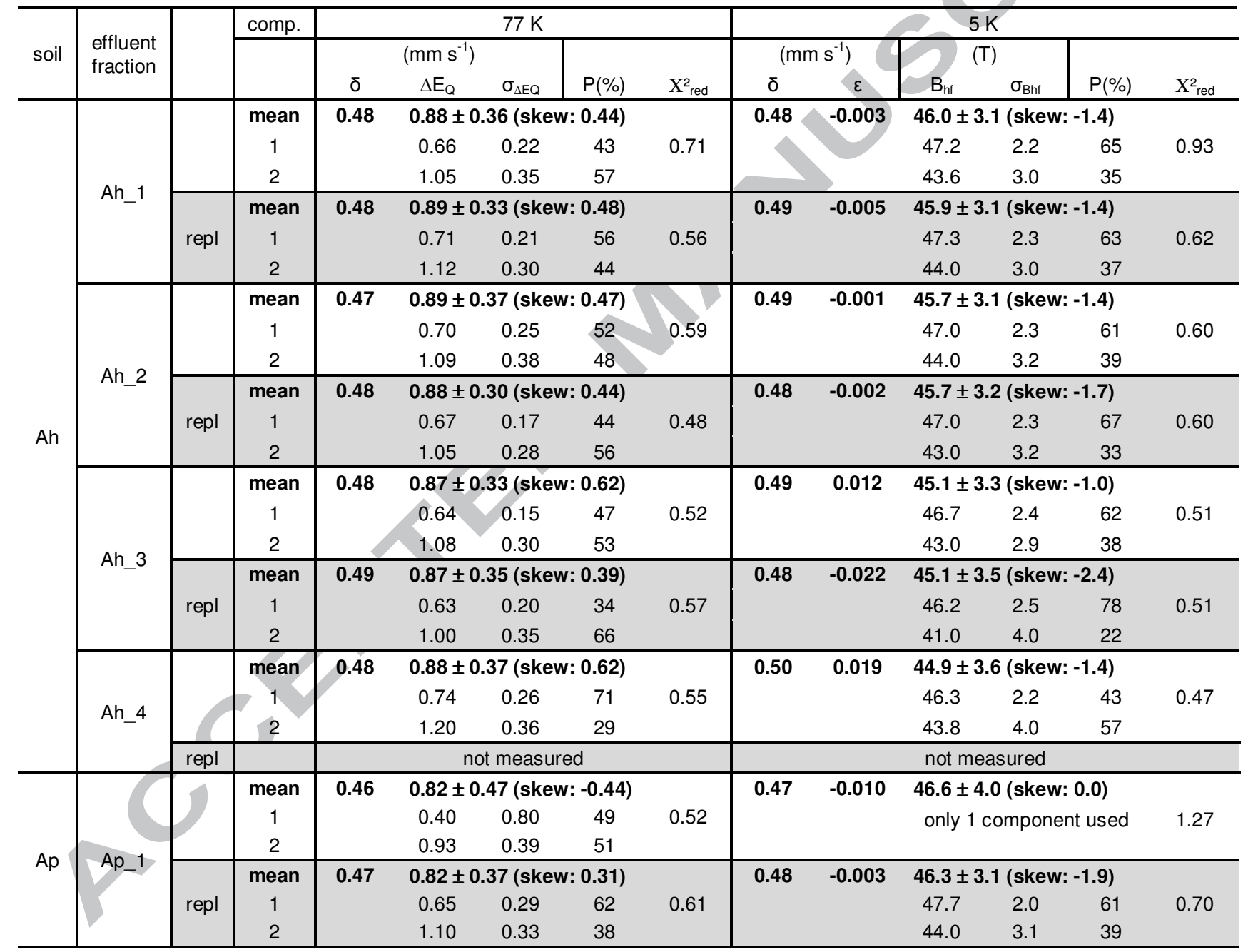



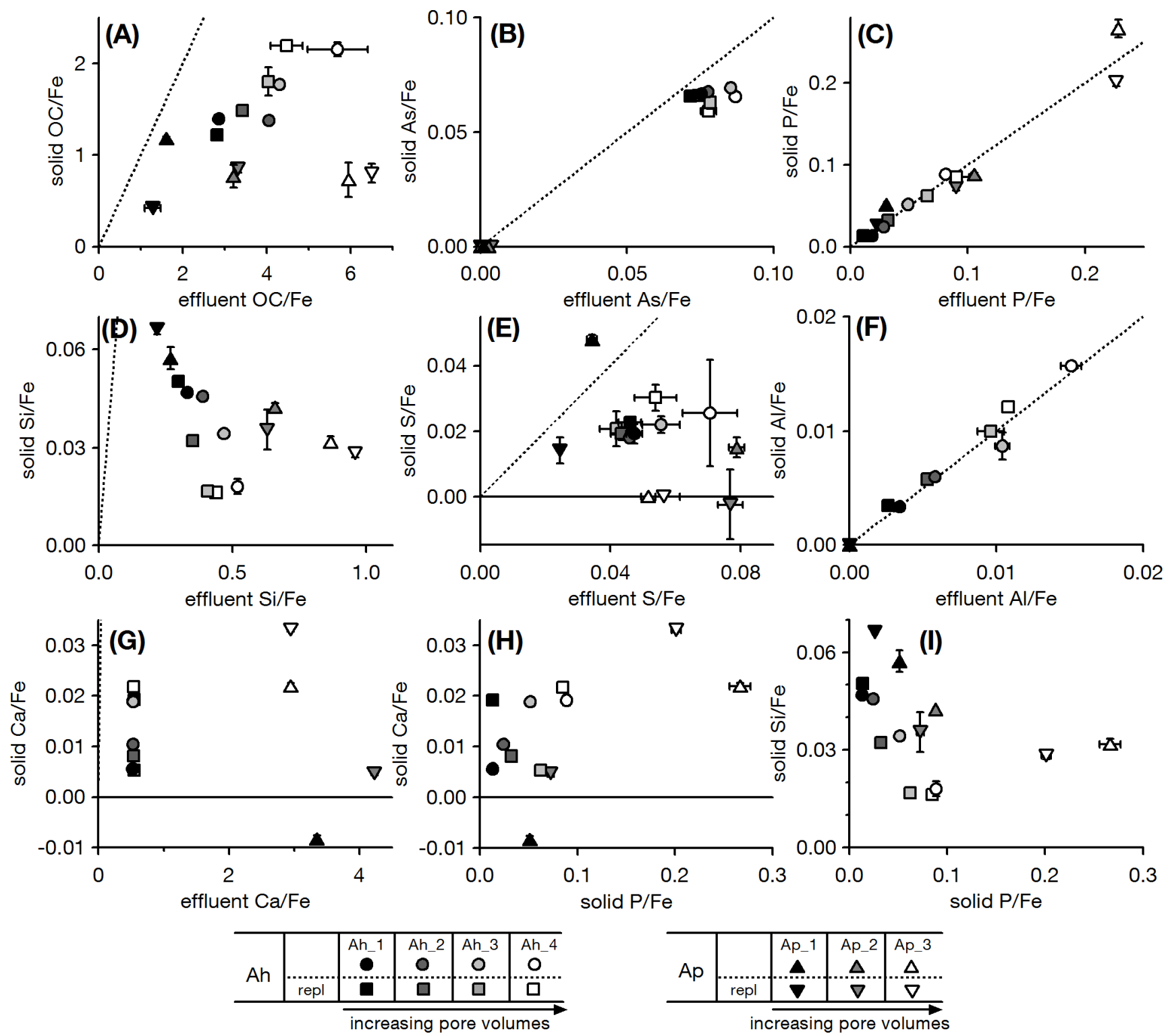

Figure 1. Mean molar contents of $(A)$ organic carbon $(O C),(B) A s,(C) P,(D) S i,(E) S$, (F) Al and (G) Ca relative to the mean molar Fe content in Fe-OM co-precipitates ("solid", y-axis) in dependence on the molar ratio of the corresponding elements and $\mathrm{Fe}$ in the effluent fractions (x-axis). Relative content of $(\mathrm{H}) \mathrm{Ca}$ and $(\mathrm{I}) \mathrm{Si}$ in dependence on the relative $\mathrm{P}$ content in the Fe-OM co-precipitates. Dashed line: 1:1 correlation. More details on the effluent fractions are given in Table 1. Error bars denote the data processing-induced propagation of analytical errors. This may result in an altered visual appearance of the markers compared to the corresponding symbols in the legend. 

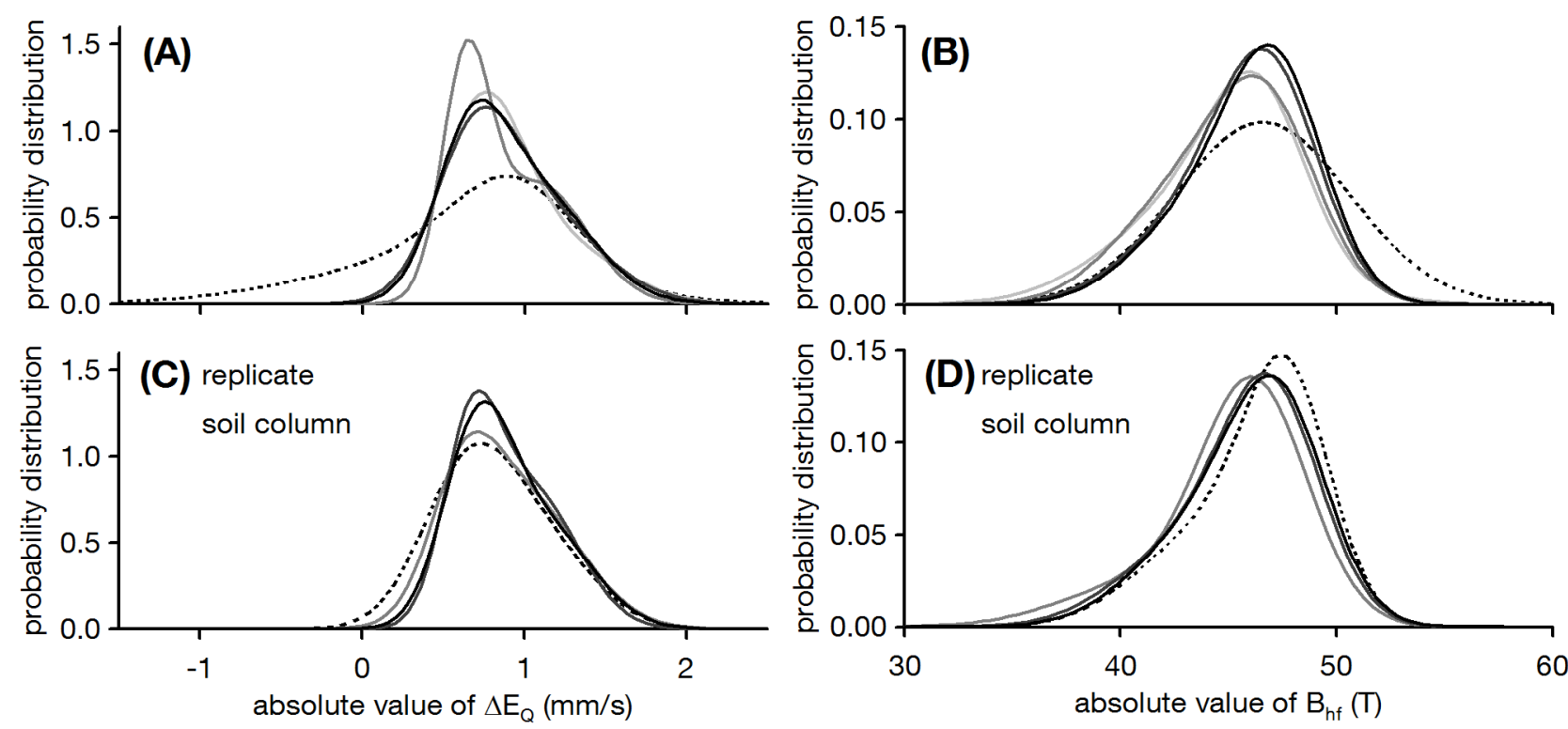

$\underset{\text { Ah_1 }}{\longrightarrow \text { Ancreasing pore volumes }}$

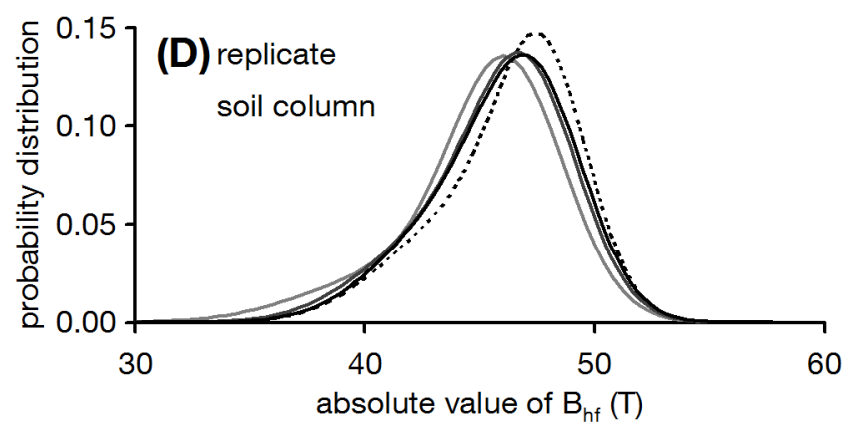

Ah_4 ……... Ap_1

Figure 2. Probability distributions $(A, C)$ of the quadrupole splittings $\left(\Delta E_{Q}\right)$ and $(B, D)$ of the magnetic hyperfine fields $\left(\mathrm{B}_{\mathrm{hf}}\right)$ in the $77 \mathrm{~K}$ - and $5 \mathrm{~K}$-Mössbauer spectra, respectively, of the Fe-OM coprecipitates from the assigned soil effluent fractions (details in Table 1). Refer to Figure EA-13 for the original Mössbauer spectra and their fits. 


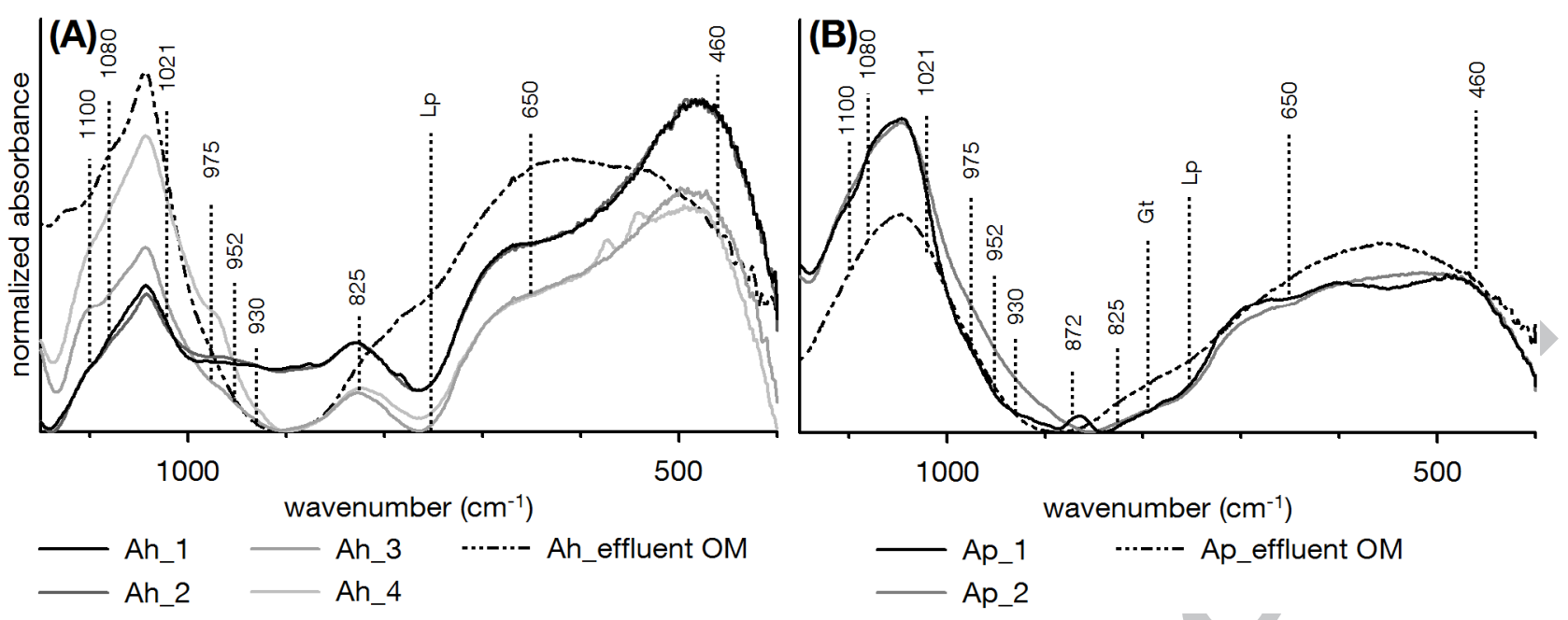

Figure 3. Transmission-FTIR spectra of material (incl. Fe-OM co-precipitates) from dialyzed effluent fractions from the topsoil material $(A)$ of the floodplain site $(A h)$ and $(B)$ of the agricultural site $(A p)$. More details on the effluent fractions are given in Table 1. Spectra of "effluent OM" were obtained from corresponding effluent fractions without Fe-OM co-precipitates (treated according to EA-7). Dashed lines: wavenumbers of interest. Lp and Gt: diagnostic bands for lepidocrocite and goethite, respectively (out-of-plane $\mathrm{OH}$-bending; Cornell and Schwertmann (2003)). For visualization purposes, FTIR spectra of effluent material from the replicate soil columns are shown in Figure EA-20. 

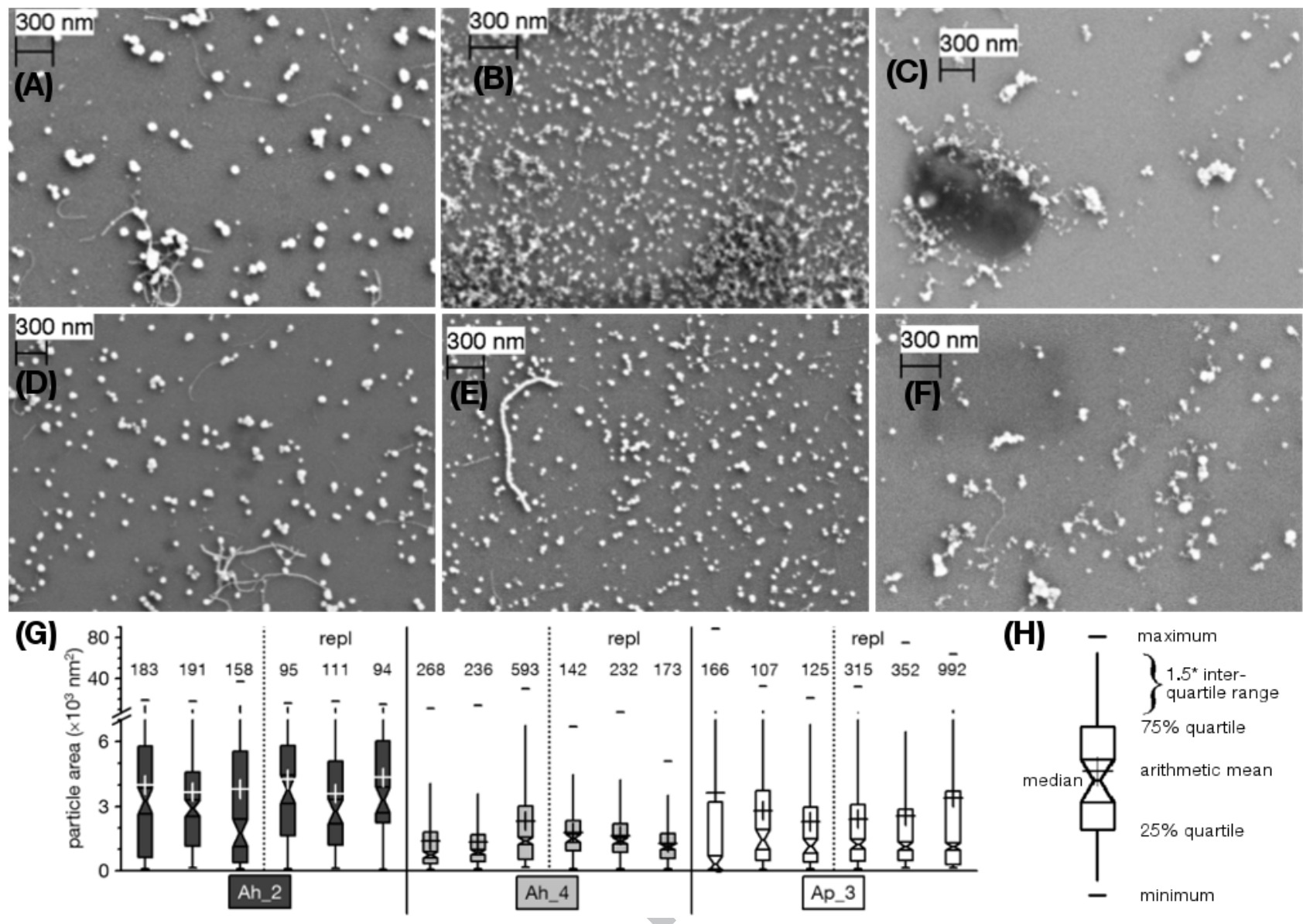

Figure 4. Secondary electron (SE) images of Fe-OM co-precipitates from soil effluents. (A) Effluent fraction Ah_2 and (B) Ah_4 from the topsoil material of the floodplain site and (C) Ap_3 from the topsoil material of the agricultural site (refer to Table 1 for details). (D-F) Corresponding effluent fractions from the replicate soil columns. (G) Size distributions of the aggregated Fe-OM coprecipitates in each effluent fraction obtained from triplicate SE image analysis. Value: number of counted aggregates. $(\mathrm{H})$ Introduction to tailed boxplots. repl: effluent from replicate soil column. 

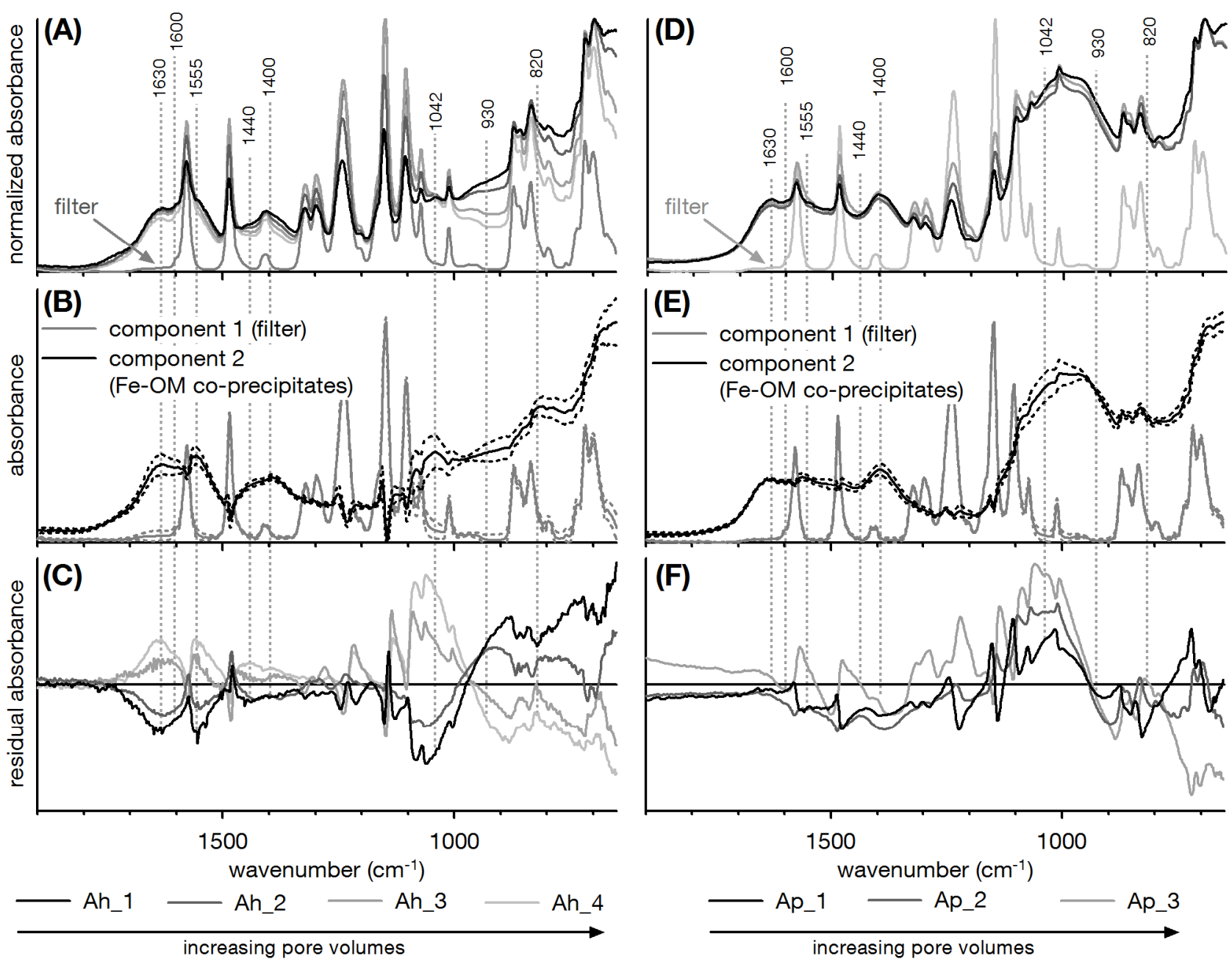

Figure 5. (A,D) ATR-FTIR spectra of polyethersulfone filters covered with Fe-OM co-precipitates. $(B, E)$ Spectra (solid line) and corresponding 95\% confidence intervals (dashed lines) of the 2 components derived from positive matrix factorization. (C,F) Difference (residual) between measured and reconstructed ATR-FTIR spectra. (A-C) refers to the effluent fractions obtained from the topsoil material of the floodplain site (Ah). (D-F) refers to the effluent fractions obtained from the topsoil material of the agricultural site (Ap; more details in Table 1). Vertical dashed lines: wavenumbers of interest. Spectra in (A) and (D) were normalized on intensity for better visualization. Original spectra and corresponding residuals can be found in Figure EA-19. For visualization purposes, FTIR spectra of the Fe-OM co-precipitates from the effluent fractions of the replicate soil column are shown in Figure EA-21. 